\title{
New insight into the support effect on HDS catalysts: evidence for the role of Mo-support interaction on the $\mathrm{MoS}_{2}$ slab morphology
}

\author{
Elizabeth Dominguez Garcia ${ }^{1}$, Jianjun Chen ${ }^{1,2}$, Erwan Oliviero $^{3}$, Laetitia \\ Oliviero,", Françoise Maugé ${ }^{1}$ \\ 1- Laboratoire Catalyse et Spectrochimie, ENSICAEN, Université de Normandie, CNRS, 6 \\ bd Maréchal Juin, 14050 Caen, France \\ 2- National Engineering Research Center of Chemical Fertilizer Catalyst, School of \\ Chemical Engineering, Fuzhou University, Fujian, China \\ 3- Université de Montpellier, CC087, Place Eugène Bataillon, 34095 Montpellier Cedex 5, \\ France
}

Abstract: $\mathrm{MoS}_{2}$ catalysts were prepared on $\mathrm{Al}_{2} \mathrm{O}_{3}, \mathrm{SiO}_{2}$ and $\mathrm{TiO}_{2}$ support. On the oxidic forms, Raman and UV-visible characterizations show the strong $\mathrm{Mo}-\mathrm{TiO}_{2}$ interaction and the weak $\mathrm{Mo}-\mathrm{SiO}_{2}$ one that leads to a poorer Mo dispersion s. $\mathrm{MoS}_{2}$ nanoparticles were then studied by TEM and adsorption of CO followed by infra-red spectroscopy which allows the distinction and quantification of the two stable edges namely the S- and M- edges. It appears that the slab morphology is strongly modified by the support nature: thus the stronger the $\mathrm{MoS}_{2}$-support interaction the higher the S-/M- edge ratio. Finally, $\mathrm{MoS}_{2}$ morphology impacts the catalytic activity in thiophene HDS: (1) an increase of the S-/M- edge ratio leads to the increase of the TOF value for Mo sulfided supported on $\mathrm{Al}_{2} \mathrm{O}_{3}$ and $\mathrm{SiO}_{2}$; (2) a specific behavior with high TOF value of mainly M-edge sites and strong hydrogenating properties is underlined for $\mathrm{Mo} / \mathrm{TiO}_{2}$.

Keywords: Hydrodesulfurization (HDS), Support effect, Molybdenum disulfide $\left(\mathrm{MoS}_{2}\right)$, Slab morphology, Sulfidation, Infrared (IR) spectroscopy, CO adsorption, Mo edge dispersion.

\section{Introduction}

Nowadays, production of ultra clean fuels is required due to the restricted governmental regulations that spread all around the world in order to protect human health and environment. Knowing that the crude oils tend to get heavier and richer in sulfur, adapted technologies have to be developed as well as new generation of hydrodesulfurization (HDS) catalysts. The development of more active HDS catalysts which typically consist in molybdenum sulfide 
dispersed on a support surface with cobalt or nickel as promoters [1] can be performed by many approaches such as changing the active component, varying preparation method, or changing the support [2].

Indeed, the nature of the support influences the metal-support interactions at the early stage of the preparation and thus modifies the final active site structure. Various hypotheses have been proposed to explain this modification such as the role of the support in the dispersion and stacking of the active phase, the influence of the acidity of the support [3] or the indirect electronic effect of the support [3,4] as reviewed by Breysse et al. [5]. These studies have underlined the high potential of $\mathrm{TiO}_{2}$ as support for sulfide catalysts $[5,6]$.

In order to rationalize the support effects, alumina and anatase- $\mathrm{TiO}_{2}$ surface interaction with Mo sulfide were compared using DFT calculations [7, 8]. In HDS conditions, the two more stable planes identified for anatase- $\mathrm{TiO}_{2}$ were hydrated (001), and non-hydrated (101), and for gamma alumina hydrated (110) and non-hydrated (100). To mimic the slab-support interaction, a single layer of triangular $\mathrm{Mo}_{6} \mathrm{~S}_{\mathrm{n}}$ cluster was chosen. Likewise, tilted epitaxial orientation was found favorable on anatase- $\mathrm{TiO}_{2}$ surfaces and parallel orientation on alumina surfaces. The epitaxial orientation is ascribed to the formation of Mo-S(O)-Ti-S(O)-Mo rings. Thus, strong and specific $\mathrm{MoS}_{2}$ anchoring with $\mathrm{TiO}_{2}$ surface can be expected and would favor the creation of sulfur depleted Mo edge sites. Classification of the strength of metal-support interaction is not straightforward: Joshi et al has proposed a scale to rationalize the concept of strong interaction (Type I support) and weak interaction (Type II supports) based on the thiolysis reaction energy. From their calculations, the formation of Mo-O-Si linkage characteristic of strong interaction is unlikely on $\mathrm{SiO}_{2}$ support and weak interaction is expected [9]. From these theoretical approaches, the order of strength of active phase-support interaction is $\mathrm{SiO}_{2}<\mathrm{Al}_{2} \mathrm{O}_{3}<\mathrm{TiO}_{2}$. Thus, these three supports differing in term of interaction with the slabs were selected for the present study.

Then, to link the catalytic activity with the structure of the catalysts, it is considered that the dispersed $\mathrm{MoS}_{2}$ nanoparticles present Mo atoms located in the basal plane that are catalytically inactive and Mo atoms located at the edge that are the active ones [1, 10, 11]. As a pioneer, Kasztelan et al. proposed that $\mathrm{MoS}_{2}$ slabs could adopt different morphology such as triangular, hexagonal, rhombohedral or chain; and that the percentage of molybdenum located at the edge of the particle (dispersion) directly depended on this morphology [12]. Moreover, this morphology accounts for the existence of two kinds of stable edges in $\mathrm{MoS}_{2}$ slab: Mo 
terminated edge (Mo-edge) and sulfur terminated edge (S-edge) with different local structure and sulfur coverage and consequently different activity [13-15]. First image of $\mathrm{MoS}_{2}$ slab morphology were recorded by Scanning Tunneling Microscopy (STM) by Lauritsen et al. [1618]. Single-layered molybdenum sulfide nanoparticles dispersed on Au (111) surface were prepared varying the sulfidation conditions: triangular morphology was favored by pure $\mathrm{H}_{2} \mathrm{~S}$ while truncated triangular morphology was favored by more reductive conditions (conventional HDS conditions). Also, STM was used to study $\mathrm{MoS}_{2}$ slab on rutile- $\mathrm{TiO}_{2}$ (110), elongated hexagonal slab morphology was observed with both S-edge and Mo-edge in the longest face of the hexagon [19]. Recently, Maugé group refined the method of adsorption of CO followed by FTIR spectroscopy (IR/CO) to distinguish Mo edge sites located in the two different edges of $\mathrm{MoS}_{2}$ nanoparticles $[10,20,21]$. Experimental vibrations are in agreement with theoretical vibrations determined by DFT calculation previously realized by Travert et al. [22, 23]. Extinction molar adsorption coefficient was calculated by Maugé et al for M-edge [21] and by Chen et al. for S-edge [11] allowing quantification of Mo located in both edges. Thus, relations between edge site concentrations determined from $\mathrm{CO}$ adsorption and catalytic activity were reported for a series of catalysts prepared on $\mathrm{Al}_{2} \mathrm{O}_{3}$ support, underlying the higher activity of Sedge sites as compared to M-edge sites for thiophene HDS [10,11]. Finally, the proportion of M-edge and S-edge detected by IR/CO can be used to determine the $\mathrm{MoS}_{2}$ model morphology and then to study its change upon different parameters such as chelating agent addition, sulfidation temperature and pressure. In an attempt to rationalize the effect of such parameters, the interaction between the slab and the support was pointed out as the crucial feature.

Therefore, this study is focused on the determination of the influence of the support nature on $\mathrm{MoS}_{2}$ slab morphology using the IR/CO method. The study is carried out using three different supports: $\mathrm{Al}_{2} \mathrm{O}_{3}$ as the reference support, $\mathrm{TiO}_{2}$ known to lead to strong slab support interaction and $\mathrm{SiO}_{2}$ as a weak interacting support. To clarify this notion of interaction, the supports alone and the oxidic forms of the three catalysts are also studied by IR, Raman and UV-Vis spectroscopy. Finally, the support influence on the activity in thiophene HDS of $\mathrm{MoS}_{2}$ catalysts is studied highlighting the effect of the $\mathrm{MoS}_{2}$ slab morphology and the specific behavior of Mo active sites on $\mathrm{TiO}_{2}$ support.

\section{Experimental}

\subsection{Catalysts preparation}


Catalysts were prepared by classical wetness impregnation method without $\mathrm{pH}$ adjustement and using heptamolybdate tretrahydrated salt (Alfa Aesar, 99\%) as molybdenum precursor. The initial $\mathrm{pH}$ of the impregnation solution was 5.5. The supports, $\gamma-\mathrm{Al}_{2} \mathrm{O}_{3}(\mathrm{Sasol}), \mathrm{SiO}_{2}$ (silica 60, Merk) and $\mathrm{TiO}_{2}$ (mixture of anatase and rutile phases, Degussa) were first sieved between 0.2 and $0.5 \mathrm{~mm}$ and calcined at $673 \mathrm{~K}$ during $3 \mathrm{~h}$ for $\mathrm{TiO}_{2}$ and $4 \mathrm{~h}$ for $\mathrm{SiO}_{2}$ and at $773 \mathrm{~K}$ during $3 \mathrm{~h}$ for $\mathrm{Al}_{2} \mathrm{O}_{3}$. The conditions of calcination were optimized to eliminate impurities minimizing the risk of phase change. Metal amount were determined in order to reach the same metal density (3 atoms $\mathrm{Mo} / \mathrm{nm}^{2}$ ) on the different supports (Table 1). After impregnation, the catalysts were dried at $383 \mathrm{~K}(3 \mathrm{~K} / \mathrm{min})$ during $16 \mathrm{~h}$ and then calcined at $673 \mathrm{~K}(3 \mathrm{~K} / \mathrm{min})$ during $4 \mathrm{~h}$.

Table 1. Textural properties and Mo and S contents of the studied catalysts

\begin{tabular}{|l|c|c|c|c|c|}
\hline \multirow{2}{*}{ Catalysts } & \multicolumn{2}{|c|}{ Surface area $\left(\mathrm{m}^{2} / \mathrm{g}\right)$} & \multirow{2}{*}{$\% \mathrm{wt} \mathrm{Mo}^{\text {a }}$} & \% wt Mo ${ }^{\mathrm{b}}$ & \multirow{2}{*}{$\mathrm{S}^{\mathrm{M}} \mathrm{Mo}^{*}$} \\
\cline { 2 - 6 } & Support & Oxide catalyst & & & \\
\hline $\mathrm{Mo} / \mathrm{Al}_{2} \mathrm{O}_{3}$ & 248 & 232 & 11 & 11 & 2.4 \\
\hline $\mathrm{Mo} / \mathrm{SiO}_{2}$ & 506 & 305 & 19 & 16 & 2.1 \\
\hline $\mathrm{Mo} / \mathrm{TiO}_{2}$ & 59 & 58 & 3 & 2 & $2.8^{*}$ \\
\hline
\end{tabular}

${ }^{\mathrm{a}}$ According to catalyst preparation ; ${ }^{\mathrm{b}}$ ICP analysis of the sulfided samples

* Atomic ratio corrected from the sulfur adsorbed on the support alone

Surface properties of the oxidic forms of the catalysts have been analyzed using $\mathrm{N}_{2}$ physisorption method. Nitrogen adsorption/desorption isotherms were measured at $77 \mathrm{~K}$ using Micrometrics Model ASAP 2020 volumetric adsorption analyzer. Elemental analyses of the exsitu sulfided samples have been carried out by inductively coupled plasma atomic emission spectrometry (ICP-AES) using a PerkinElmer Optima 330DV ICP instrument.

The ex-situ standard procedure of sulfidation was carried out in a glass reactor under $10 \%$ $\mathrm{H}_{2} \mathrm{~S} / \mathrm{H}_{2}$ flow $\left(30 \mathrm{ml} / \mathrm{min}\right.$ ) at $623 \mathrm{~K}$ for $2 \mathrm{~h}$ (heating rate $3 \mathrm{~K} / \mathrm{min}$ ). After flushing the sample by $\mathrm{N}_{2}$ and closing the reactor, this latter is transferred inside a glove box under Ar flow in order to prepare the samples for subsequent analysis (ICP-AES, Transmission Electron Microscopy) minimizing air contact.

\subsection{Infrared spectroscopy of adsorbed $\mathrm{CO}(\mathrm{IR} / \mathrm{CO})$}


Infrared (IR) characterizations were performed in a glass cell adapted for activation at high temperature and probe adsorption at low temperature $(\sim 100 \mathrm{~K})$. The sample was introduced as a wafer of around $10 \mathrm{mg}$ (precisely weight) and $2 \mathrm{~cm}^{2}$. To study the support and the oxide catalyst, the activation procedure consisted in an evacuation at $623 \mathrm{~K}\left(473 \mathrm{~K}\right.$ for $\mathrm{TiO}_{2}$ in order to keep the proportion of rutile and anatase forms constant) for $2 \mathrm{~h}$. For the study of the sulfided samples, the in-situ sulfidation procedure is similar to the ex-situ standard procedure described previously. After this sulfidation step, two different post-treatments could be applied. The sulfided sample was maintained at $623 \mathrm{~K}$ while the cell was flushed with Ar (10 minutes) and then evacuated (30 minutes). Then, the post-treatment was performed under either $2 \%$ $\mathrm{H}_{2} \mathrm{~S} / \mathrm{H}_{2}$ or pure hydrogen flow $(30 \mathrm{ml} / \mathrm{min})$ at $623 \mathrm{~K}$ for $2 \mathrm{~h}$.

After all these activation procedures, the catalyst was flushed with Ar during 10 minutes, let under vacuum $1 \mathrm{~h}$ at $623 \mathrm{~K}$ (residual pressure: $1.10^{-4} \mathrm{~Pa}$ ) and then cooled down to $100 \mathrm{~K}$ to perform $\mathrm{CO}$ adsorption. $\mathrm{CO}$ adsorption experiments were performed by introducing small calibrated $\mathrm{CO}$ doses up to an equilibrium pressure of $133 \mathrm{~Pa}$. IR spectra were recorded with a Thermo Nicolet Nexus FT-IR spectrometer equipped with a MCT detector. All spectra were normalized to a disc of $5 \mathrm{mg} / \mathrm{cm}^{2}$. All experiments were duplicated; the experimental uncertainty is estimated to $5 \%$. For quantitative analysis, spectra corresponding to catalyst at full coverage in $\mathrm{CO}$ were decomposed using OMNIC program and pseudo-Voigt function.

\subsection{UV-VIS spectroscopy}

Ultraviolet-visible (UV-Vis) spectra were recorded with a Cary 4000 spectrometer from Varian. The spectrum acquisition was done between $800-200 \mathrm{~nm}$ with a speed of $300 \mathrm{~nm} / \mathrm{min}$. The analysis was performed on the oxide catalysts under atmospheric conditions, and taking the corresponding support as reference for each Mo/support. UV-Vis spectra $(F(R)$ vs $\lambda)$ were converted in $[F(R) h v]^{2}$ vs $h v$ in order to get the edge adsorption energy [24]. The edge absorption energy is determined by finding the energy intercept of a straight line fitting the low energy rise in the graphs of $[\mathrm{F}(\mathrm{R}) \mathrm{h} v]^{2} \mathrm{vs} h v$.

\subsection{Raman spectroscopy}

Raman spectroscopy was performed on the oxidic catalysts using a Jobin Yvon Labram 300 Raman spectrometer equipped with a confocal microscope, an Nd-YAG laser $(\lambda=532 \mathrm{~nm})$ and a CCD detector. Spectra were recorded under air at ambient conditions. 


\subsection{Thiophene HDS test}

The oxidic catalysts (around $50 \mathrm{mg}$ precisely weighted), sieved between 0.2 and $0.5 \mathrm{~mm}$, were introduced in the plug flow reactor and sulfided in situ. Sulfidation was performed at 623 $\mathrm{K}$ under $10 \% \mathrm{H}_{2} \mathrm{~S} / \mathrm{H}_{2}(30 \mathrm{ml} / \mathrm{min})$ during $2 \mathrm{~h}$ at $\mathrm{P}_{\mathrm{atm}}$, according to the standard protocol. Thiophene reaction was carried out at $623 \mathrm{~K}$ (same temperature as the sulfidation) and $\mathrm{P}_{\mathrm{atm}}$. Thiophene was introduced into the reactor by passing $70 \mathrm{~mL} \cdot \mathrm{min}^{-1}$ of $\mathrm{H}_{2}$ flow through a thiophene saturator maintained at $291 \mathrm{~K}$ and mixed with a flow of $20 \mathrm{~mL} \cdot \mathrm{min}^{-1}$ of $10 \% \mathrm{H}_{2} \mathrm{~S} / \mathrm{H}_{2}$ giving a thiophene partial pressure of $8 \mathrm{kPa}$ in a mixture of hydrogen $(91.2 \mathrm{kPa})$ and $\mathrm{H}_{2} \mathrm{~S}(2.1$ $\mathrm{kPa}$ ). Introduction of low amount of $\mathrm{H}_{2} \mathrm{~S}$ in the feed is performed to avoid leveling of the activity through $\mathrm{H}_{2} \mathrm{~S}$ formation. The outlet gas was analysed by a Varian 3900 gas chromatograph equipped with flame ionization (FID) detector. The reaction rate was calculated as $\mathrm{r}_{\mathrm{HDS}}=(\mathrm{F} / \mathrm{m}) \cdot \mathrm{X}$, where $\mathrm{F} / \mathrm{m}$ is the molar flow rate of thiophene per gram of catalyst and $\mathrm{X}$ is thiophene conversion which is below $5 \%$. Thiophene reaction was running during $18 \mathrm{~h}$ to obtain the reaction rate at steady state. Relative error on the rate determination is $5 \%$. For rate calculation, the mass of catalyst measured initially was corrected by the mass loss due to sulfidation considering the mass loss fraction determined in the IR experiments.

\subsection{Transmission Electron Microscopy (TEM)}

Transmission electron microscopy (TEM) was performed on a JEOL 2200 FS FEG operated at $200 \mathrm{kV}$. All studied samples were sulfided at $623 \mathrm{~K}$ according to the ex-situ standard procedure previously described. The catalyst was then poured in absolute ethanol inside the Ar box and TEM analyses were carried out using a few drops of this suspension on a copper grid. TEM images from different parts of the catalyst were recorded on a $4092 \times 4092$ $\mathrm{px}^{2}$ GATAN Ultrascan CCD camera at the same magnification. Slab length and stacking degree distributions of sulfide slabs were determined from at least 300 slabs for $\mathrm{Mo} / \mathrm{Al}_{2} \mathrm{O}_{3}$ and $\mathrm{Mo} / \mathrm{SiO}_{2}$ catalysts, and 120 slabs for $\mathrm{Mo} / \mathrm{TiO}_{2}$ catalyst. '

\section{Results}

\subsection{Oxidic catalysts}

\subsubsection{Textural properties}

Surface areas of the catalysts in oxidic form are summarized in Table 1 and compared with that of the support. It is worth noticing that the surface area of $\mathrm{Mo} / \mathrm{SiO}_{2}$ significantly decreases 
after the preparation step. This can be due to the low pore size of the support (around $6 \mathrm{~nm}$ ) in comparison with the size of the oxomolybdate species.

\subsubsection{IR spectroscopy of oxidic catalysts}

The support surfaces were studied by $\mathrm{CO}$ adsorption at low temperature followed by FTIR spectroscopy (IR/CO) to distinguish Lewis and Brønsted acid sites (supplementary results). Then, to study the metallic species-support interaction in oxidic catalysts, $\mathrm{CO}$ adsorption spectra at equilibrium pressure $(133 \mathrm{~Pa})$ for the support and calcined catalyst are compared in Figure 1 and Figure 2. Compared to pure $\mathrm{Al}_{2} \mathrm{O}_{3}$, calcined $\mathrm{Mo} / \mathrm{Al}_{2} \mathrm{O}_{3}$ catalyst shows an intensity decrease of the $v(\mathrm{CO})$ band ascribed to Lewis acid sites $\left(\mathrm{Al}^{3+}\right)$ at $2182 \mathrm{~cm}^{-1}$, as well as strong decrease of the $v(\mathrm{CO})$ band attributed to Brønsted acid sites $(\mathrm{OH})$ at $2155 \mathrm{~cm}^{-1}$. This indicates that oxomolybdate species are in interaction with both Lewis acid sites and Brønsted acid sites as it is reported in the literature for high Mo loading [25]. Likewise, calcined $\mathrm{Mo} / \mathrm{SiO}_{2}$ catalyst shows a strong decrease of the $v(\mathrm{CO})$ band ascribed to hydroxyl groups of $\mathrm{SiO}_{2}$.

A)

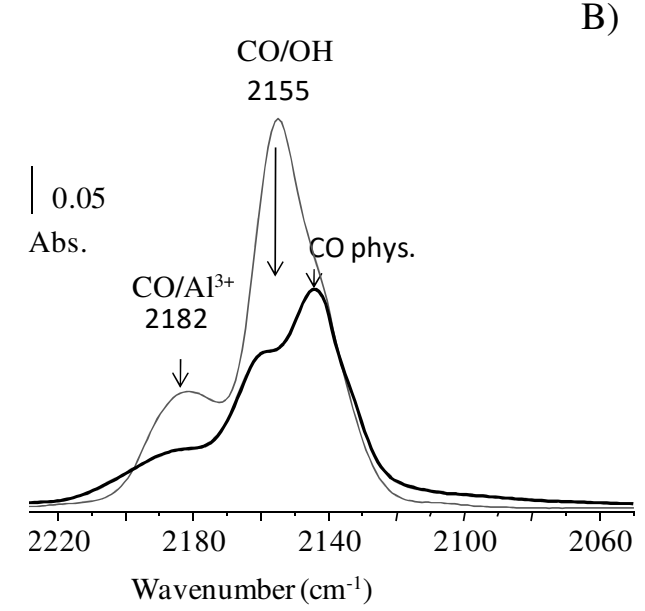

B)

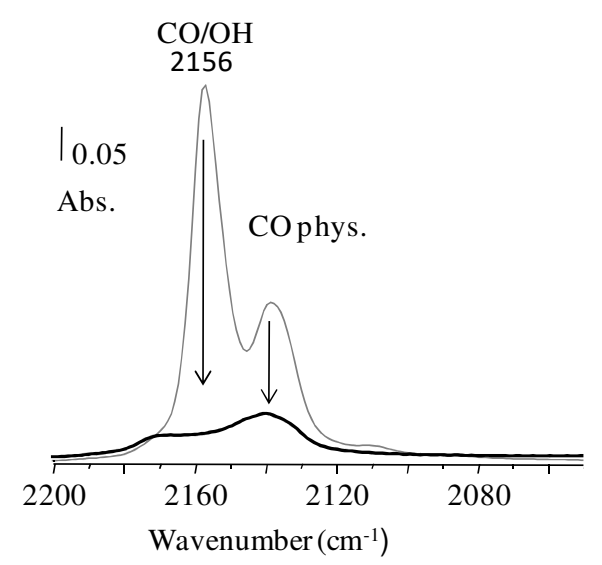

Figure 1. IR spectra of CO adsorption (100K, $133 \mathrm{~Pa}$ ) on support (grey line) and corresponding Mo catalyst (black line) after calcination at $623 \mathrm{~K}$. A- $\mathrm{Al}_{2} \mathrm{O}_{3}$ and $\mathrm{Mo}_{\mathrm{A}} \mathrm{Al}_{2} \mathrm{O}_{3} ; \mathrm{B}-\mathrm{SiO}_{2}$ and $\mathrm{Mo} / \mathrm{SiO}_{2}$

Finally, Figure 2 presents the IR spectra of $\mathrm{CO}$ adsorption on $\mathrm{TiO}_{2}$ and $\mathrm{Mo} / \mathrm{TiO}_{2}$ catalyst in oxidic form. On the oxide catalyst, the intensity of the $v(\mathrm{CO})$ band at $2182 \mathrm{~cm}^{-1}$ that is ascribed to Lewis acid sites $\left(\mathrm{Ti}^{4+}\right)$ is strongly decreased indicating that $\mathrm{Ti}^{4+}$ cations are involved in the anchoring of oxomolybdate species. Meanwhile, it is noticeable that the $\mathrm{CO}$ vibration band at $2158 \mathrm{~cm}^{-1}$ of acid hydroxyl groups does not present any intensity modification, although a small broadening toward higher wavenumber is noticeable. 


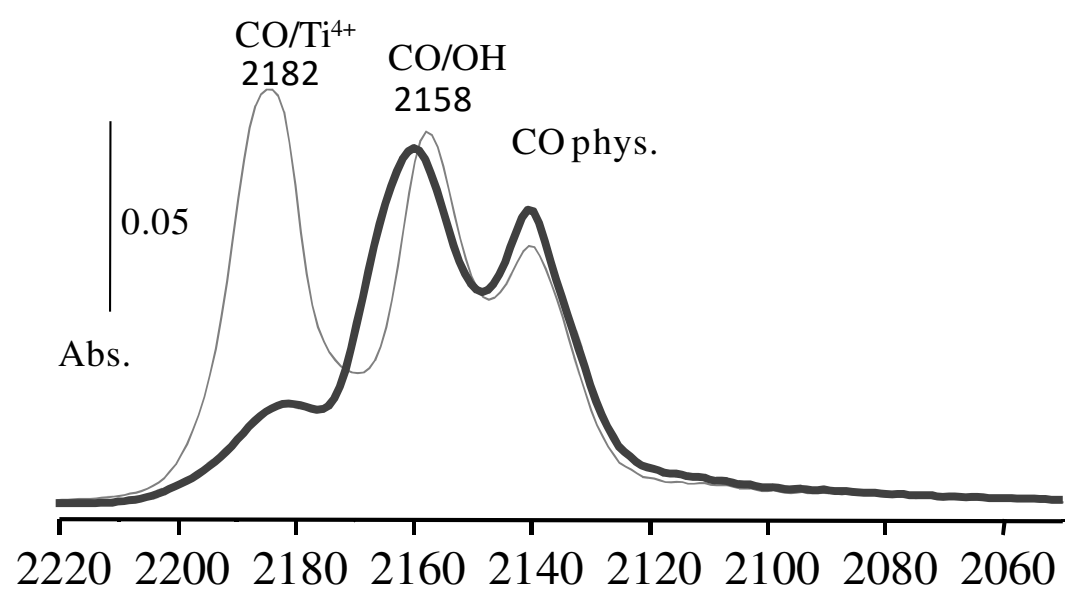

Wavenumber $\left(\mathrm{cm}^{-1}\right)$

Figure 2. IR spectra of $\mathrm{CO}$ adsorption $\left(100 \mathrm{~K}, 133 \mathrm{~Pa}\right.$ ) on $\mathrm{TiO}_{2}$ (grey line) and $\mathrm{Mo} / \mathrm{TiO}_{2}$ catalyst (black line) after calcination at $473 \mathrm{~K}$.

\subsubsection{Raman spectroscopy}

After calcination and before sulfidation, molybdenum can be present under different forms on the support surface: $\left(\mathrm{MoO}_{4}\right)^{-2},\left(\mathrm{Mo}_{7} \mathrm{O}_{24}\right)^{6-},\left(\mathrm{Mo}_{2} \mathrm{O}_{7}\right)^{2-}, \mathrm{MoO}_{3}$. The presence of some $\mathrm{MoO}_{3}$ particles is characteristic of poorly dispersed molybdenum species while the other ones correspond to well-dispersed molybdenum species, $\left(\mathrm{Mo}_{7} \mathrm{O}_{24}\right)^{6-}$ and $\left(\mathrm{Mo}_{2} \mathrm{O}_{7}\right)^{2-}$ being referred as polymolybdate species.

Raman spectra of the oxidic catalysts are shown in Figure 3. Raman spectrum of $\mathrm{Mo} / \mathrm{Al}_{2} \mathrm{O}_{3}$ presents two bands characteristic of polymolybdate species at 958 and $856 \mathrm{~cm}^{-1}$ which are attributed to $\mathrm{Mo}=\mathrm{O}$ and $\mathrm{Mo}-\mathrm{O}-\mathrm{Mo}$ vibrations, respectively. As previously mentioned, the formation of polymolybdate species is characteristic of a good dispersion of the metal on the alumina surface [26]. Similar species appear on $\mathrm{Mo} / \mathrm{TiO}_{2}$, as revealed by the two bands at 965 and $874 \mathrm{~cm}^{-1}$, but with a positive shift of around $10 \mathrm{~cm}^{-1}$ in comparison with polymolybdate species present on $\mathrm{Mo} / \mathrm{Al}_{2} \mathrm{O}_{3}$. This positive shift has been previously ascribed to a support effect and interpreted by a strong interaction between $\mathrm{TiO}_{2}$ surface and polymolybdate species [27]. The size of the clusters of these polymolybdate species appears somehow different on $\mathrm{Mo} / \mathrm{Al}_{2} \mathrm{O}_{3}$ and on $\mathrm{Mo} / \mathrm{TiO}_{2}$ since the intensity ratio of the two Raman bands are changed $\left(\mathrm{I}_{\mathrm{Mo}=\mathrm{O}} / \mathrm{I}_{\mathrm{Mo}-\mathrm{O}-\mathrm{Mo}}=3.2\right.$ and 2.2 respectively): smaller polymolybdate clusters are thus expected on $\mathrm{Mo} / \mathrm{Al}_{2} \mathrm{O}_{3}$ than on $\mathrm{Mo} / \mathrm{TiO}_{2}$. By contrast, on $\mathrm{Mo} / \mathrm{SiO}_{2}$, two different molybdenum species are 
formed as illustrated in Figure 3: As on the previous catalysts, polymolybdate species are formed. Note that the position of the band attributed to Mo-O-Mo $\left(866 \mathrm{~cm}^{-1}\right)$ is intermediate compared to that on $\mathrm{Mo} / \mathrm{Al}_{2} \mathrm{O}_{3}$ and on $\mathrm{Mo} / \mathrm{TiO}_{2} . \mathrm{MoO}_{3}$ is also detected as indicated by the two sharp bands at $997 \mathrm{~cm}^{-1}$ and $821 \mathrm{~cm}^{-1}$ characteristics of $\mathrm{Mo}=\mathrm{O}$ and Mo-O-Mo vibrations in $\mathrm{MoO}_{3}[28,29]$. The formation of $\mathrm{MoO}_{3}$ accounts for the lower dispersion of molybdenum when deposited on silica. 

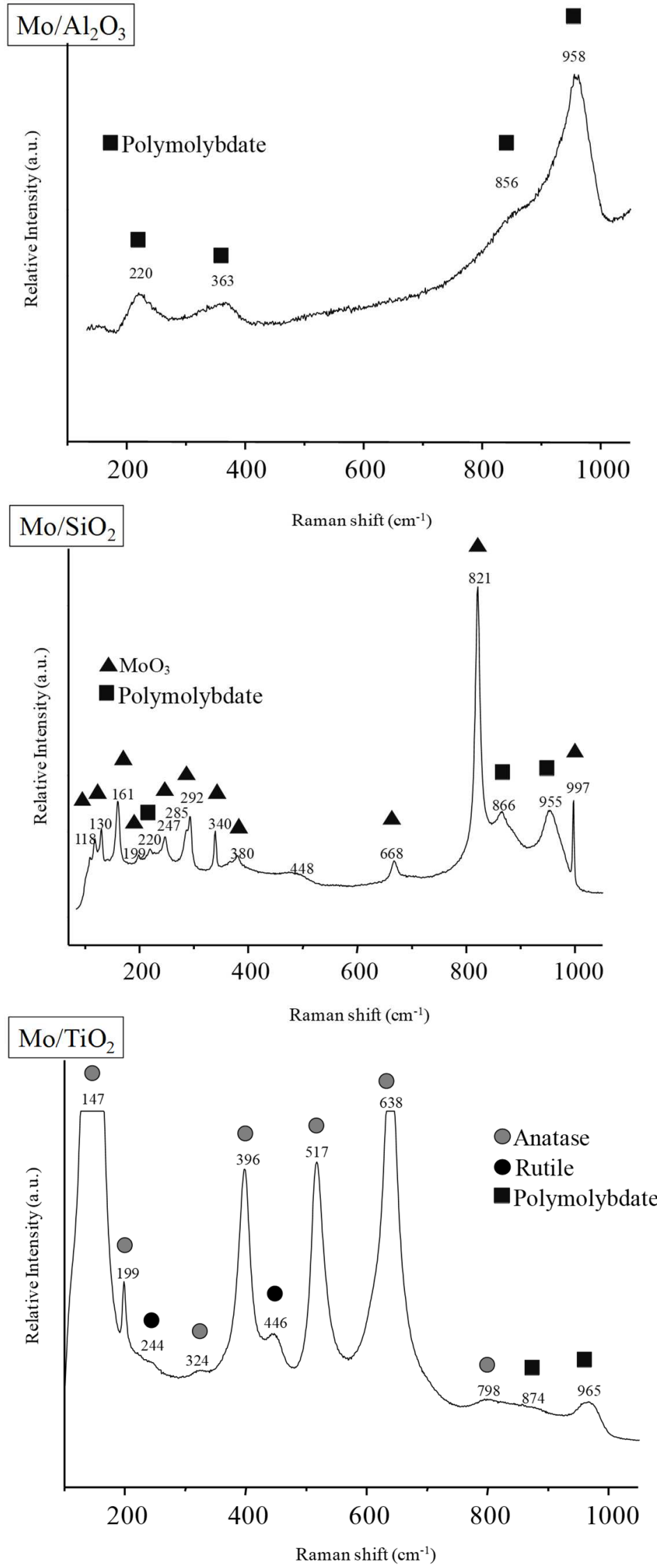

Figure 3. Raman spectra of oxide catalysts 


\subsubsection{UV-Vis spectroscopy}

Oxide catalysts were characterized by UV-Vis spectroscopy to identify the nature of the molybdenum species and the size of the (poly)molybdate clusters (Figure 4).
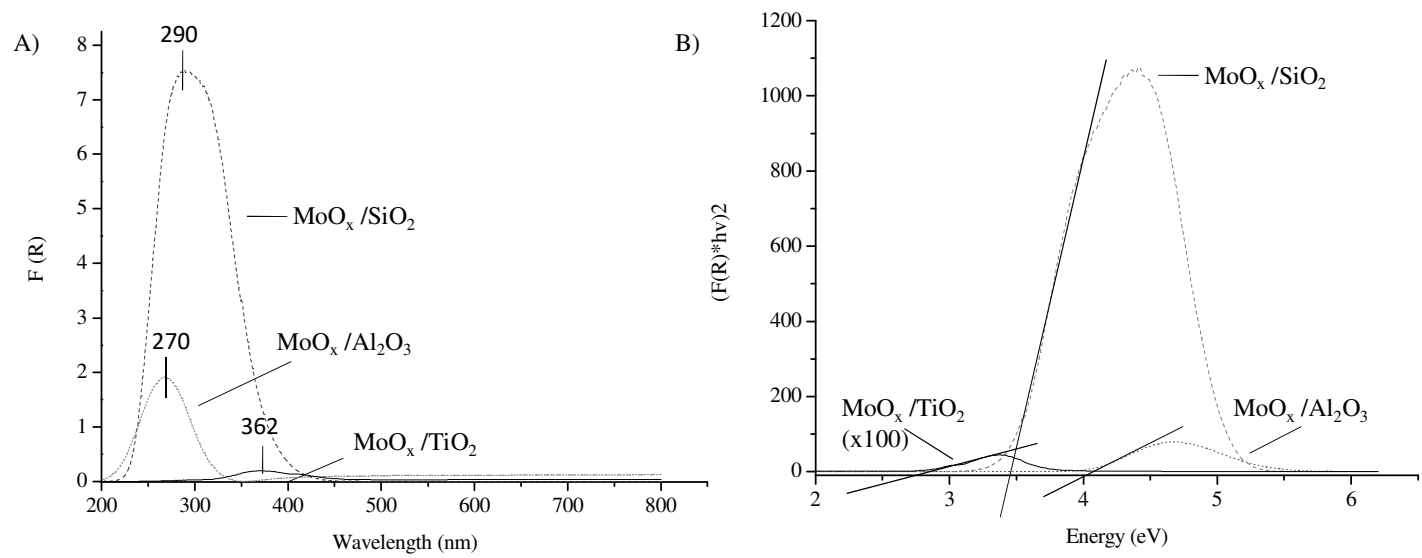

Figure 4. A) UV-VIS spectra and B) Edge energy calculation on $\mathrm{Mo}_{2} \mathrm{Al}_{2} \mathrm{O}_{3}, \mathrm{Mo} / \mathrm{SiO}$, and $\mathrm{Mo} / \mathrm{TiO}_{2}$ oxide catalysts.

For all catalysts, the UV-Vis spectra show one broad band with maximum intensity at 270, 290 and $362 \mathrm{~nm}$ for $\mathrm{Mo} / \mathrm{Al}_{2} \mathrm{O}_{3}, \mathrm{Mo} / \mathrm{SiO}_{2}$ and $\mathrm{Mo} / \mathrm{TiO}_{2}$ respectively due to the presence of oxomolybdate species. From these spectra, the so-called edge absorption energy is determined by finding the energy intercept of a straight line fitted through the low energy rise in the graphs of $[F(R) \cdot h v]^{2}$ vs hv Figure 4B). Indeed, UV-Vis spectroscopy can inform on the different sizes of the molybdenum anion clusters present on the surface through the analysis of the optical band gap energy determined from the position of the low energy rise in UV-Vis spectrum: a decrease of the band gap energy corresponds to an increase in the cluster size or oxide domain $[24,30]$. Thus, edge absorption energy has been previously determined for known clusters of molybdenum and plotted versus the average number of nearest Mo neighbors in the clusters. An empirical, linear correlation between edge absorption energy (E) and the local degree of aggregation of the Mo entities measured by the number of nearest Mo neighbors ( $\mathrm{N}_{\text {Mo neighbours) }}$ has been obtained: $\mathrm{N}_{\text {Mo neighbours }}=16-3.8 \mathrm{E}$ as given in Figure $5[24,30]$. 
Figure 5 also plots the corresponding edge absorption energy for the Mo species formed on the three oxide catalysts of this study. The molybdenum species on $\mathrm{Mo} / \mathrm{Al}_{2} \mathrm{O}_{3}$ has the highest average edge energy of $4 \mathrm{eV}$, followed by the ones on $\mathrm{Mo} / \mathrm{SiO}_{2}$ with $3.2 \mathrm{eV}$ and finally the one on $\mathrm{Mo} / \mathrm{TiO}_{2}$ with $2.9 \mathrm{eV}$. From these results, it can be deduced that on $\mathrm{Mo} / \mathrm{TiO}_{2}$, polymolybdate species are large entities since they present a high number of Mo neighbors (around 5) that correspond to the formation of $\mathrm{MoO}_{6} \mathrm{O}_{19}{ }^{2-}$ and $\mathrm{Mo}_{7} \mathrm{O}_{24}{ }^{6-}$ species. By contrast, the polymolybdate species formed on $\mathrm{Mo} / \mathrm{Al}_{2} \mathrm{O}_{3}$ oxide catalyst are small entities. Indeed, they present a Mo neighbor number around one that can correspond to the formation of $\mathrm{MoO}_{4}{ }^{2-}$ and $\mathrm{Mo}_{2} \mathrm{O}_{7}{ }^{2-}$ species. The later species is more probable since the characteristic bands at 840 and $1000 \mathrm{~cm}^{-1}$ of distorted $\mathrm{MoO}_{4}{ }^{2-}$ were not detected in the Raman spectra [26]. The ranking of the size of the polymolybdate entities is in agreement with Raman observations. However, Mo neighbor number for $\mathrm{Mo} / \mathrm{Al}_{2} \mathrm{O}_{3}$ is surprisingly low as compared to the value of 6 reported by Weber et al. [31] for a similarly prepared sample. Finally, simultaneous presence of $\mathrm{MoO}_{3}$ clusters (edge energy of $3 \mathrm{eV}$ ) and heptamolybdate species (edge energy of $3.3 \mathrm{eV}$ ) is revealed on the oxidic $\mathrm{Mo} / \mathrm{SiO}_{2}$ by the intermediate value of edge energy $(3.2 \mathrm{eV})$ on this catalyst. The presence of $\mathrm{MoO}_{3}$ clusters for this sample is in accordance with the Raman results.

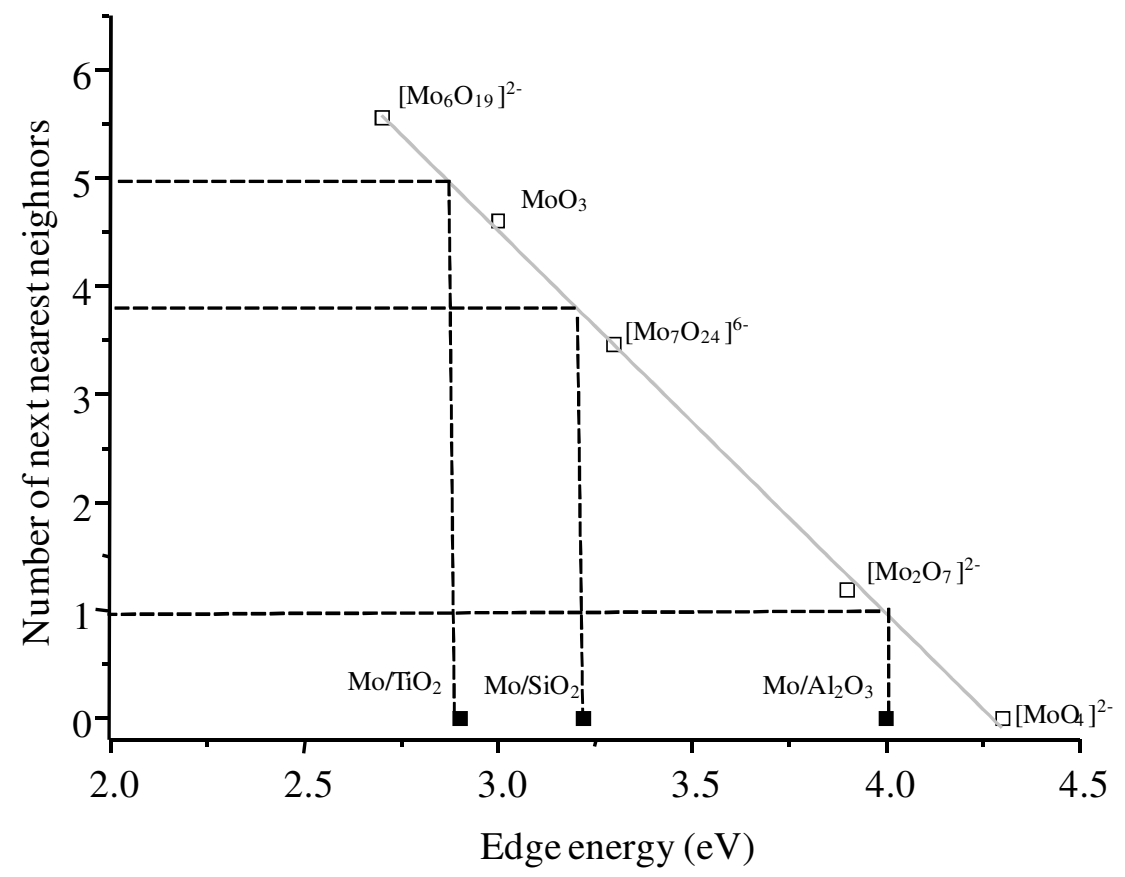

Figure 5. Relationship between the number of Mo nearest neighbors and the edge energy of standard molybdenum compounds in solution [30] and Mo species for Mo supported on $\mathrm{Al}_{2} \mathrm{O}_{3}$, $\mathrm{SiO}_{2}$ or $\mathrm{TiO}_{2}$. 


\subsection{Sulfide catalysts}

\subsubsection{Elemental analysis}

Molybdenum and sulfur contents of the sulfide catalysts were determined by ICP analysis as shown in Table 1 . The metal content of the sulfide catalysts are in line with the metal loading used during impregnation.

All the catalysts present an S/Mo atomic ratio greater than 2 that can even reach 2.8 on $\mathrm{Mo} / \mathrm{TiO}_{2}$. Note that in this later case, the sulfur amount detected on the support alone after $\mathrm{H}_{2} \mathrm{~S} / \mathrm{H}_{2}$ treatment $(0.16 \mathrm{wt} \% \mathrm{~S})$ was subtracted. So, this high S/Mo ratio likely indicates a sulfidation of the support that is favored in presence of the $\mathrm{MoS}_{2}$ phase. This hypothesis is in accordance with the formation of TiSx detected by XPS in the work of Ninh et al [32].

\subsubsection{Thiophene HDS activity}

Figure 6 shows the thiophene conversion rate obtained for Mo catalysts supported on alumina, silica and titania. Thiophene conversion rate is given per surface area since all catalysts were prepared with the same metal density, 3 atoms $\mathrm{Mo} / \mathrm{nm}^{2}$. It appears that $\mathrm{Mo} / \mathrm{TiO}_{2}$ catalyst is four times more active than the other two catalysts. These results are in accordance with previously reported results by Ninh et al. [32].

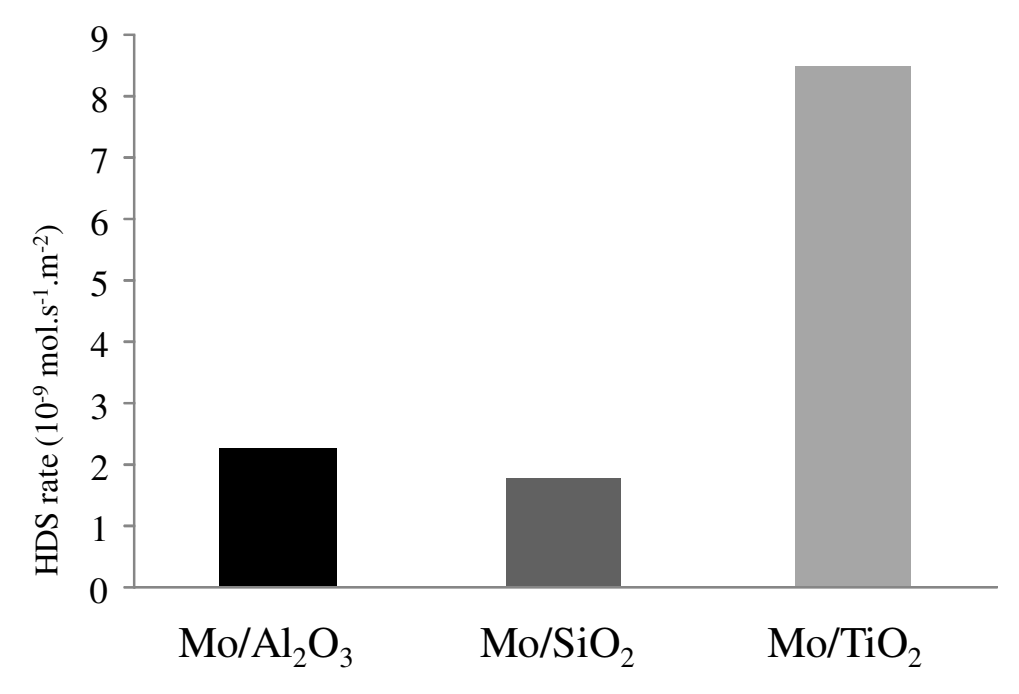

Figure 6. Thiophene reaction rate on sulfided Mo catalysts.

It is well-known that thiophene is not an optimal model molecule to study the selectivity of catalysts in HDS reaction since the different reaction routes, namely the hydrogenation (HYD) and direct desulfurization (DDS) routes, are not strictly parallel. However, a significant 
increase of THT selectivity was detected for $\mathrm{Mo} / \mathrm{TiO}_{2}$ catalyst while the thiophene conversion remains in a similar range $(5-10 \%)$ for the three catalysts. THT being an intermediate product formed on HYD route, this marked change allows to show that the hydrogenation steps are favored compared to $\mathrm{C}-\mathrm{S}$ bond cleavage steps on $\mathrm{Mo} / \mathrm{TiO}_{2}$ as compared to $\mathrm{Mo} / \mathrm{Al}_{2} \mathrm{O}_{3}$ and $\mathrm{Mo} / \mathrm{SiO}_{2}$ (Figure 7). Accordingly, the ratio butane/butenes is also increased on $\mathrm{Mo} / \mathrm{TiO}_{2}$ as compared to $\mathrm{Mo} / \mathrm{Al}_{2} \mathrm{O}_{3}$ and $\mathrm{Mo} / \mathrm{SiO}_{2}$ catalysts. The high hydrogenating properties of $\mathrm{Mo} / \mathrm{TiO}$ have been also underlined by Castillo-Villalon and al. in HDS of DBT and 4,6-DMDBT [33].

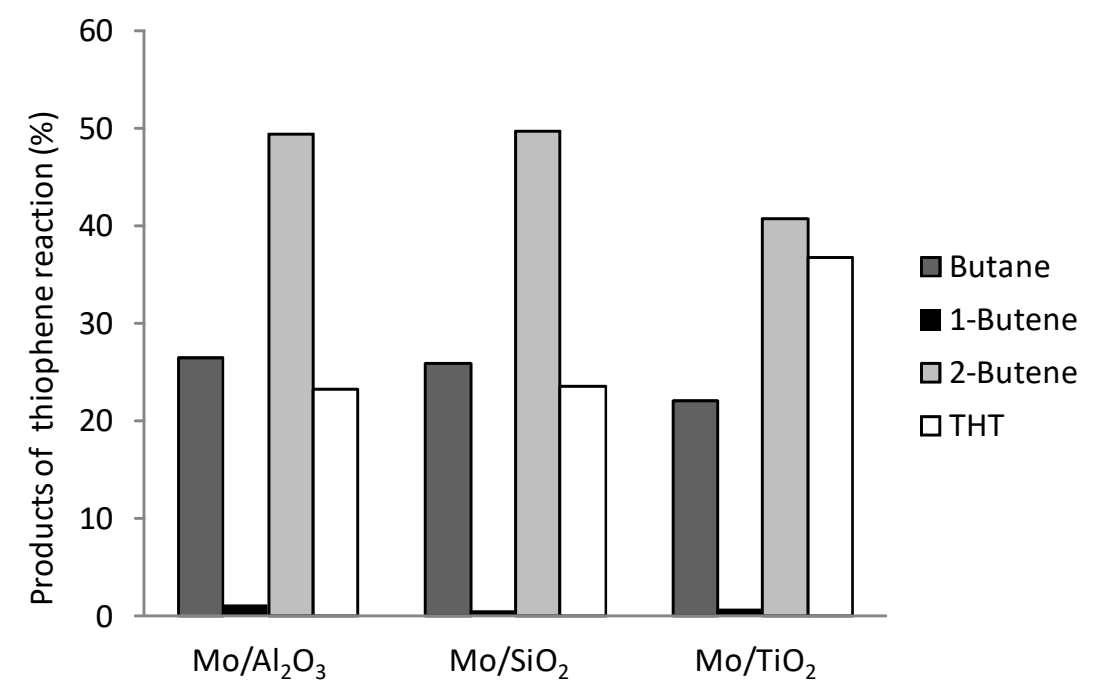

Figure 7. Percentage of the different products formed in the thiophene reaction on sulfided Mo catalysts.

As mentioned before, $\mathrm{TiO}_{2}$ is sulfided during $\mathrm{Mo} / \mathrm{TiO}_{2}$ sulfidation process. As shown by Ziolek et al, the molecular adsorption of $\mathrm{H}_{2} \mathrm{~S}$ generates Brønsted acidity that could be involved in the hydrogenation process [34]. Then, thiophene test was also carried out on sulfided $\mathrm{TiO}_{2}$ alone to check if the extra THT formation coming from $\mathrm{Mo} / \mathrm{TiO}_{2}$ catalyst could be linked with sulfided $\mathrm{TiO}_{2}$ activity. First, the HDS rate obtained on sulfided $\mathrm{TiO}_{2}$ was almost zero, 0.27 $\mathrm{mol} / \mathrm{h} . \mathrm{kg}_{\text {cat }}$ instead of $2.9 \mathrm{~mol} / \mathrm{h} . \mathrm{g}_{\text {cat }}$ on $\mathrm{Mo} / \mathrm{TiO}_{2}$. On the other hand, sulfided $\mathrm{TiO}_{2}$ presented much lower selectivity for THT than $\mathrm{Mo} / \mathrm{TiO}_{2}$ (supplementary materials, Table SM1). Knowing that THT is formed before butenes and butane in the reaction scheme, it can be concluded, even if the conversions were an order of magnitude different, that sulfided $\mathrm{TiO}_{2}$ is not responsible on its own for the favored hydrogenation step on $\mathrm{Mo} / \mathrm{TiO}_{2}$ catalyst. 


\subsubsection{IR/CO of sulfide catalysts}

\section{a. IR/CO after in-situ sulfidation}

$\mathrm{CO}$ adsorption was performed on the three catalysts after in-situ sulfidation. Figure 8 presents the IR spectra obtained on $\mathrm{Mo} / \mathrm{Al}_{2} \mathrm{O}_{3}$ catalyst for increasing $\mathrm{CO}$ doses up to saturation under equilibrium pressure. Two domains can be distinguished: that between 2240 and 2145 $\mathrm{cm}^{-1}$ accounts for the interaction of CO with the support, and that between 2130 and $1950 \mathrm{~cm}^{-1}$ that corresponds to the $\mathrm{CO}$ in interaction with $\mathrm{MoS}_{2}$ nanoparticles. The frequency of $\mathrm{CO}$ in interaction with Mo sites is sensitive to their coordination and environment, and two main $\mathrm{CO} / \mathrm{Mo}$ bands can be distinguished. From previous work, the interaction with Mo sites located on M-edge is characterized by a $v(\mathrm{CO})$ band at $2114 \mathrm{~cm}^{-1}$, while the interaction with Mo sites located on S-edge is characterized by a $v(\mathrm{CO})$ band at $2070 \mathrm{~cm}^{-1}$. Also, others bands are detected at lower wavenumbers i.e. 2040, 2021, and $1996 \mathrm{~cm}^{-1}$ which are attributed to Mo located in S-edge with lower sulfur coverage and metallic Mo respectively [35].

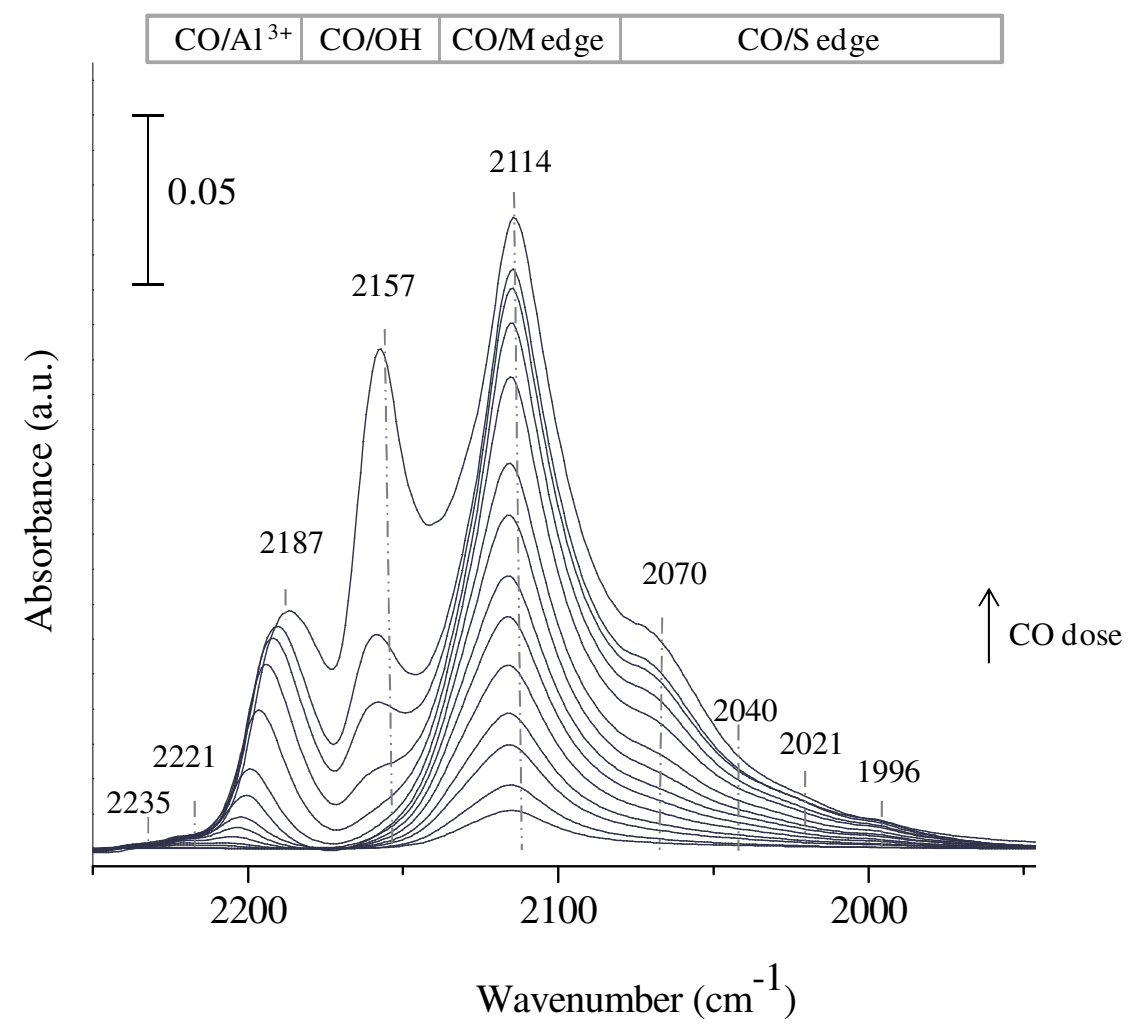

Figure 8. IR spectra after adsorption at $100 \mathrm{~K}$ of increasing doses of CO up to saturation (133 Pa) on $\mathrm{Mo}_{\mathrm{Al}} \mathrm{l}_{2} \mathrm{O}_{3}$ sulfided at $623 \mathrm{~K}$ under $10 \% \mathrm{H}_{2} \mathrm{~S}_{\mathrm{H}} \mathrm{H}_{2}$

Figure 9 shows the IR spectra of $\mathrm{CO}$ adsorbed on sulfided $\mathrm{Mo} / \mathrm{SiO}_{2}$. The high wavenumber zone accounts for $\mathrm{CO}$ in interaction with $\mathrm{Si}-\mathrm{OH}$ groups with a $v(\mathrm{CO})$ band at $2155 \mathrm{~cm}^{-1}$, and for 
physisorbed $\mathrm{CO}$ with a band around $2134 \mathrm{~cm}^{-1}$. At lower wavenumber, the $v(\mathrm{CO} / \mathrm{Mo})$ bands present frequencies close to the ones obtained for $\mathrm{MoS}_{2}$ sites on $\mathrm{Al}_{2} \mathrm{O}_{3}$. So, CO/Mo on M-edge appears at $2115 \mathrm{~cm}^{-1}$ and in S-edge at 2065, 2040 and $2020 \mathrm{~cm}^{-1}$. The band ascribed to metallic Mo also appeared at $1997 \mathrm{~cm}^{-1}$. Note that the proportion of these $v(\mathrm{CO} / \mathrm{Mo})$ contributions are different for $\mathrm{Mo} / \mathrm{SiO}_{2}$ catalyst as compared to $\mathrm{Mo} / \mathrm{Al}_{2} \mathrm{O}_{3}$ : the low wavenumber contributions (2065-1997) $\mathrm{cm}^{-1}$ being more intense as compared to $v\left(\mathrm{CO} / \mathrm{M}\right.$-edge) band on $\mathrm{Mo} / \mathrm{SiO}_{2}$ catalyst.

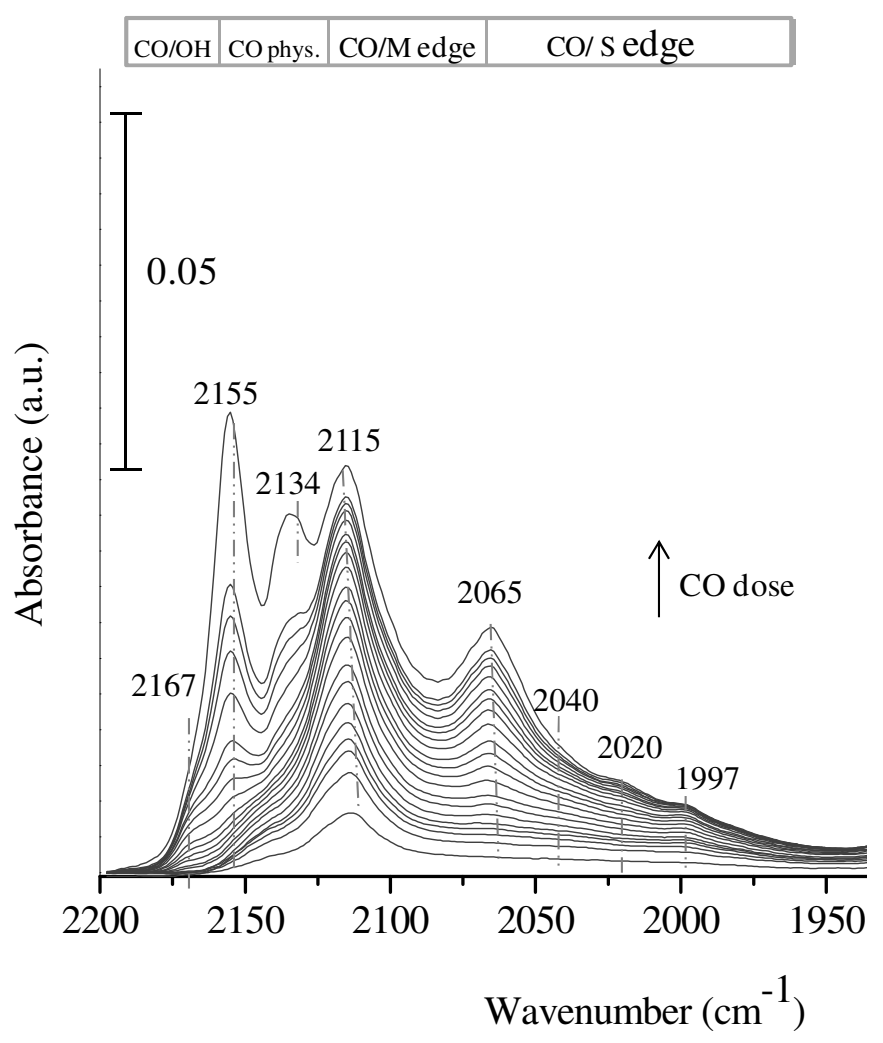

Figure 9. IR spectra after adsorption at $100 \mathrm{~K}$ of increasing doses of $\mathrm{CO}$ up to saturation (133 Pa) on $\mathrm{Mo} / \mathrm{SiO}_{2}$ sulfided at $623 \mathrm{~K}$ under $10 \% \mathrm{H}_{2} \mathrm{~S}_{2} \mathrm{H}_{2}$

Figure 10 presents the spectra of $\mathrm{CO}$ adsorption obtained on sulfided $\mathrm{Mo} / \mathrm{TiO}_{2}$. On the oxidic catalyst as well as on titania support, $\mathrm{CO}$ interaction with $\mathrm{Ti}^{4+}$ acid sites gives rise to a the $v(\mathrm{CO})$ band at $2183 \mathrm{~cm}^{-1}$ while that with Ti-OH gives rise to a main $v(\mathrm{CO})$ band at 2158 $\mathrm{cm}^{-1}$ (Figure 2). In the case of the sulfided $\mathrm{Mo} / \mathrm{TiO}_{2}$ catalyst, these two contributions present small intensity and are only detected at CO saturation. By contrast, a band at $2162 \mathrm{~cm}^{-1}$ is clearly observed from the first $\mathrm{CO}$ doses. These results can be understood taking into account that sulfidation of titania surface occurs. Indeed, Ziolek et al has reported that $\mathrm{H}_{2} \mathrm{~S}$ is mainly molecularly adsorbed on $\mathrm{Ti}^{4+}$ [34]. This is in accordance with the strong decrease of the 
$v\left(\mathrm{CO} / \mathrm{Ti}^{4+}\right)$ band upon $\mathrm{H}_{2} \mathrm{~S} / \mathrm{H}_{2}$ treatment observed on the support alone (supplementary materials, Figure SM 2). $\mathrm{H}_{2} \mathrm{~S}$ adsorption also hinders adsorption of $\mathrm{CO}$ on the $\mathrm{OH}$ groups ascribed to the contribution at $2158 \mathrm{~cm}^{-1}$ but not the one leading to the contribution at $2162 \mathrm{~cm}^{-}$ 1. Interestingly, regarding the interaction between $\mathrm{CO}$ and the $\mathrm{MoS}_{2}$ phase, mostly $\mathrm{CO}$ in interaction with Mo located at M-edge is detected on this catalyst, with only a small-detected contribution of CO/Mo located in S-edge at $2069 \mathrm{~cm}^{-1}$. CO/M-edge interaction appears at 2118 $\mathrm{cm}^{-1}$, i.e. at higher wavenumber in comparison with the two others catalysts. This shift to higher wavenumber accounts for a decrease of the back-donation of Mo to CO that indicates a decrease of the electron density of Mo when deposited on titania. This decrease of Mo electron density can be explained either by a strong interaction with the support or by the increase of coordination number of the Mo site i.e. a high sulfur coverage at the edge. However, the later hypothesis is in contradiction with the reported high $\mathrm{S}$ depletion of the $\mathrm{M}$-edge on $\mathrm{TiO}_{2}$ [8]. Note that a parallel with the shift of the peaks associated with polymolybdate species observed for the catalyst in oxidic form in Raman spectrum can be made: this shift was also attributed in the literature to the metal-support interaction [27].

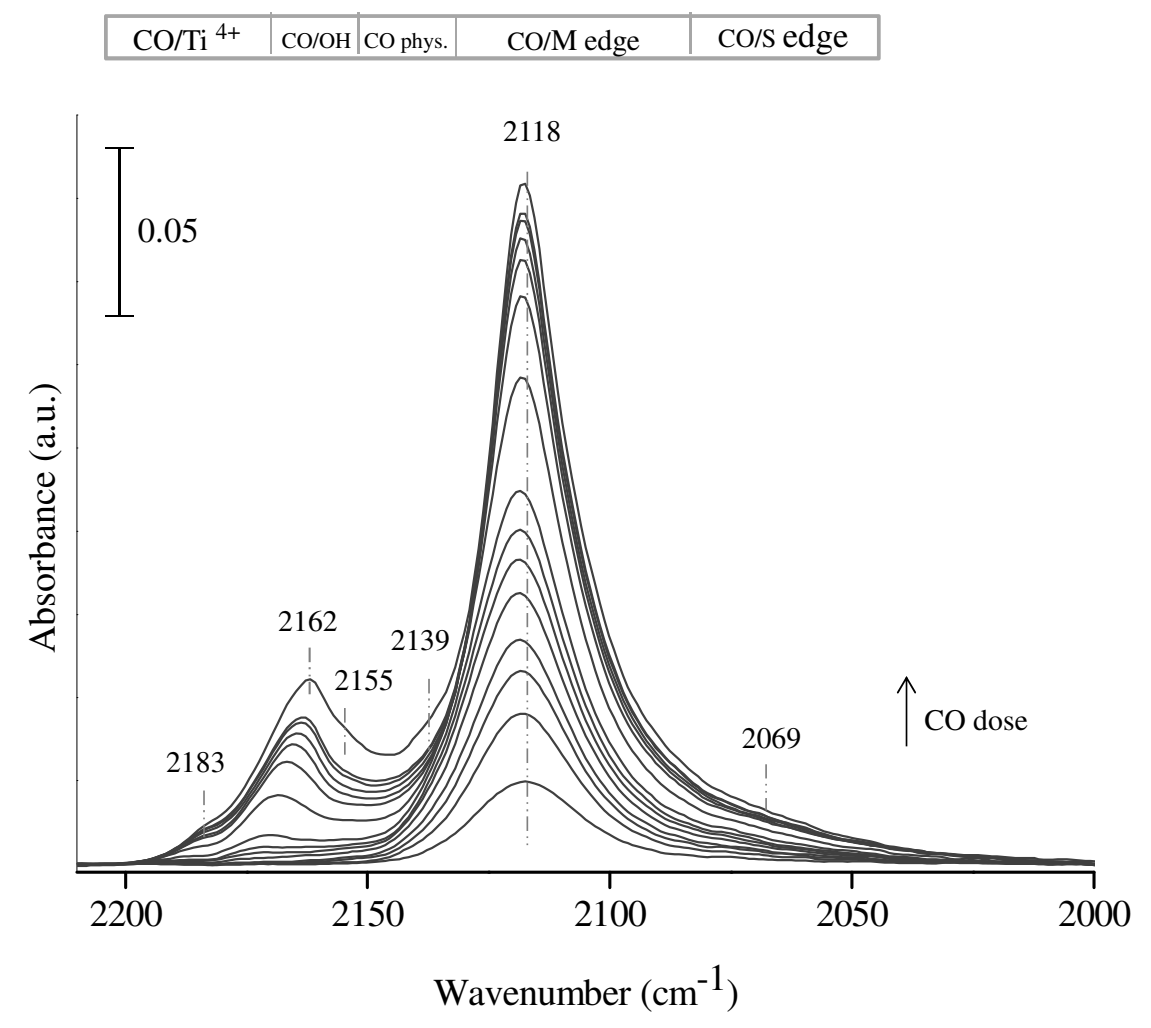

Figure 10. IR spectra after adsorption at $100 \mathrm{~K}$ of increasing doses of CO up to saturation (133 Pa) on $\mathrm{Mo} / \mathrm{TiO}_{2}$ sulfided at $623 \mathrm{~K}$ under $10 \% \mathrm{H}_{2} \mathrm{~S}_{/} \mathrm{H}_{2}$ 
In summary, CO/Mo adsorption clearly shows different S- over M- edge band intensities according to the catalysts that reveal different morphologies of the $\mathrm{MoS}_{2}$ phases according to the support nature. Mo located on both edges are detected for $\mathrm{Mo} / \mathrm{Al}_{2} \mathrm{O}_{3}$ and $\mathrm{Mo} / \mathrm{SiO}_{2}$, while Sover M- edge band intensities is greater for $\mathrm{Mo} / \mathrm{SiO}_{2}$ than for $\mathrm{Mo} / \mathrm{Al}_{2} \mathrm{O}_{3}$. Instead, mostly Mo sites on $\mathrm{M}$-edge are detected for $\mathrm{Mo} / \mathrm{TiO}_{2}$ catalyst. Quantification of each type of edge will be given later on.

\section{b. Effect of the sulfo-reductive $\left(2 \% \mathrm{H}_{2} \mathrm{~S}_{/} \mathrm{H}_{2}\right)$ and reductive post-treatments}

The sulfur coverage at the edges of $\mathrm{MoS}_{2}$ nanoparticles depends on the $\mathrm{H}_{2} \mathrm{~S} / \mathrm{H}_{2}$ molar ratio of the gas phase in equilibrium with the catalyst. Thus, this equilibrium plays on the concentration of Mo CUS sites available for CO adsorption. So, the influence of sulforeductive treatments on the total amount of $\mathrm{MoS}_{2}$ sites and on the ratio S-/M- edges has been studied. For that two different post-treatments of the catalyst were performed after the sulfidation under $10 \% \mathrm{H}_{2} \mathrm{~S} / \mathrm{H}_{2}$ : the first one mimicking the thiophene HDS reaction conditions with a $2 \% \mathrm{H}_{2} \mathrm{~S} / \mathrm{H}_{2}$ molar ratio and the second one with pure hydrogen.

Figure 11 shows the effect of these sulfo-reductive post-treatments for the three sulfide catalysts. For $\mathrm{Mo} / \mathrm{Al}_{2} \mathrm{O}_{3}$ catalyst (Figure 11), a marked effect is observed for $v(\mathrm{CO} / \mathrm{Mo}$ ) bands. After the $2 \% \mathrm{H}_{2} \mathrm{~S} / \mathrm{H}_{2}$ post-treatment, no modification in band positions is noted in comparison with the ones after sulfidation. The main $v\left(\mathrm{CO} / \mathrm{M}\right.$-edge) band appears at $2114 \mathrm{~cm}^{-1}$ and $\mathrm{CO} / \mathrm{S}-$ edge vibration band at $2070 \mathrm{~cm}^{-1}$. By contrast, after the pure $\mathrm{H}_{2}$ post-treatment, these bands shift to lower wavenumber $\left(2110\right.$ and $\left.2065 \mathrm{~cm}^{-1}\right)$ and a supplementary one is detected at 2098 $\mathrm{cm}^{-1}$. After the $2 \% \mathrm{H}_{2} \mathrm{~S} / \mathrm{H}_{2}$ post-treatment, an increase in intensity of all the $v(\mathrm{CO} / \mathrm{Mo})$ bands is observed, although in lesser extent than the increase occurring after $\mathrm{H}_{2}$ treatment.

Thereby, the highest effect can be detected after the pure $\mathrm{H}_{2}$ post-treatment as was reported in previous studies $[10,23]$. The increase factor of the $v(\mathrm{CO} / \mathrm{M}$-edge $)$ band intensity was calculated around 2 and is consistent with the one reported by Dujardin [10]. This intensity increase is ascribed to a decrease of the sulfur coverage upon $\mathrm{H}_{2}$ post-treatment that allows more Mo edge sites to be detected by CO. A lesser extent of band intensity increase is noticed for $v(\mathrm{CO} / \mathrm{S}$-edge $)$ as previously reported. Also, reducing sulfur coverage leads to a shift to lower wavenumber of the $v\left(\mathrm{CO} / \mathrm{MoS}_{2}\right)$ bands [37]. This can be explained by the increase of the electron density of the S-depleted Mo sites that leads to a stronger back donation effect to adsorbed $\mathrm{CO}$. 
For $\mathrm{Mo} / \mathrm{SiO}_{2}$ catalyst (Figure 11), post-treatment effects are close to those reported for $\mathrm{Mo} / \mathrm{Al}_{2} \mathrm{O}_{3}$ : (i) $2 \% \mathrm{H}_{2} \mathrm{~S} / \mathrm{H}_{2}$ post-treatment does not lead to any change in $v(\mathrm{CO})$ band position while an increase of the two CO/Mo band intensities is detected, (ii) after $\mathrm{H}_{2}$ post-treatment, similar shifts in band positions are noted: CO/Mo bands appear at 2110 and $2065 \mathrm{~cm}^{-1}$ and a new contribution is detected at $2102 \mathrm{~cm}^{-1}$, (iii) a strong increase of the band intensities is also observed after $\mathrm{H}_{2}$ post-treatment.

While the effect of the post-treatments is limited to small modification of $v(\mathrm{CO})$ band intensities on the support sites for $\mathrm{Al}_{2} \mathrm{O}_{3}$ and $\mathrm{SiO}_{2}$, Figure 11 shows that the $\mathrm{H}_{2}$ post-treatment modifies the surface sites of $\mathrm{TiO}_{2}$. Indeed, two $v(\mathrm{CO})$ bands appear at $2181 \mathrm{~cm}^{-1}$ and $2157 \mathrm{~cm}^{-1}$, while the band at $2162 \mathrm{~cm}^{-1}$ markedly decreases. This points out that $\mathrm{H}_{2}$ treatment eliminates the adsorbed $\mathrm{H}_{2} \mathrm{~S}$ species formed during the $\mathrm{H}_{2} \mathrm{~S} / \mathrm{H}_{2}$ treatment leading to a recovery of the $\mathrm{Ti}^{4+}$ sites and $\mathrm{TiOH}$ groups. It is also noticeable that the post-treatments of $\mathrm{Mo} / \mathrm{TiO}_{2}$ catalyst affects somewhat differently the $\mathrm{MoS}_{2}$ sites than in the case of the catalysts supported on alumina and silica. As for the band position, the effects are similar to what is observed for the alumina and silica-supported catalysts. Indeed, $2 \% \mathrm{H}_{2} \mathrm{~S}_{\mathrm{H}} \mathrm{H}_{2}$ treatment does not change the CO/Mo band position, while after $\mathrm{H}_{2}$ post-treatment, the CO/M-edge band downshifts from $2118 \mathrm{~cm}^{-1}$ to $2111 \mathrm{~cm}^{-1}$, the S-edge band from 2070 to $2065 \mathrm{~cm}^{-1}$ and a new band appears at $2098 \mathrm{~cm}^{-1}$. But, surprisingly, very limited increase of $\mathrm{CO} / \mathrm{Mo}$ band intensity is detected after $\mathrm{H}_{2}$ post-treatment. 

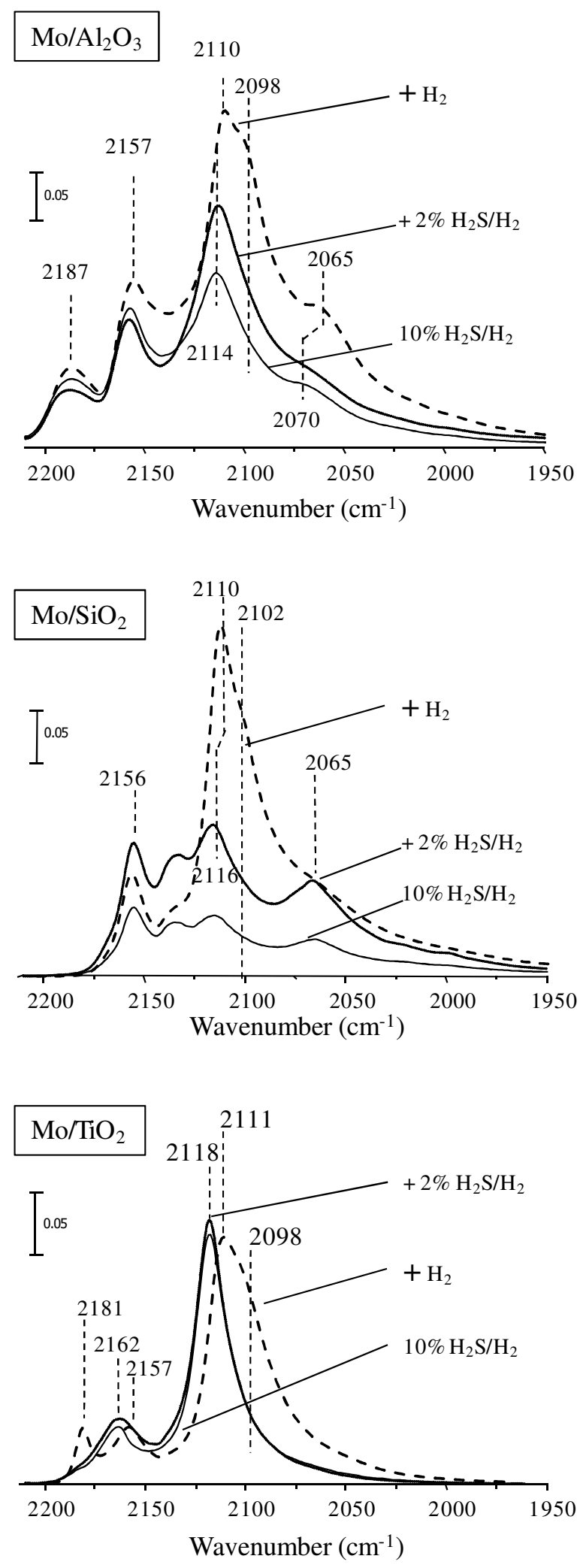

Figure 11. IR spectra of CO adsorption (100K, $133 \mathrm{~Pa}$ ) after conventional sulfidation (black full line) and after sulfidation followed by $2 \% \mathrm{H}_{2} \mathrm{~S} / \mathrm{H}_{2}$ post-treatment: (grey full line) or $\mathrm{H}_{2}$ post-treatment (dotted line) for $\mathrm{Mo}_{\mathrm{A}} \mathrm{Al}_{2} \mathrm{O}_{3}, \mathrm{Mo} / \mathrm{SiO}$, and $\mathrm{Mo} / \mathrm{TiO}_{2}$ 


\section{c. Quantification of M- and S- edge Mo sites}

Finally, the quantification of the M-edge and S-edge Mo sites was carried out using the molar extinction coefficients of $\mathrm{CO}$ adsorption bands, i.e. $16 \pm 4 \mathrm{~mol}^{-1} \cdot \mathrm{cm}$ for $v(\mathrm{CO} / \mathrm{M}$-edge $)$ calculated by Maugé et al. using $\mathrm{Mo} / \mathrm{Al}_{2} \mathrm{O}_{3}$ catalyst [21], and $35 \pm 4 \mathrm{~mol}^{-1} \cdot \mathrm{cm}$ for $v(\mathrm{CO} / \mathrm{S}$ edge) calculated by Chen et al using $\mathrm{Mo} / \mathrm{Al}_{2} \mathrm{O}_{3}$ catalyst prepared with citric acid [11]. Note that the molar extinction coefficient for $v(\mathrm{CO} / \mathrm{M}$-edge $)$ was recalculated in the present study from the results on $\mathrm{Mo} / \mathrm{Al}_{2} \mathrm{O}_{3}$ and same value $\left(15 \pm 4 \mathrm{~mol}^{-1} \cdot \mathrm{cm}\right)$ was obtained. Similarly, on $\mathrm{Mo} / \mathrm{TiO}_{2}$ catalyst the value obtained for $v(\mathrm{CO} / \mathrm{M}$-edge $)$ at $2118 \mathrm{~cm}^{-1}$ was $15 \pm 4 \mathrm{~mol}^{-1} \cdot \mathrm{cm}$, which is again in the same range. Note that the absence of change of molar extinction coefficient value with the support is in controversy to the results reported by Castillo et al. [36] that calculate different molar extinction coefficient for $\mathrm{Mo} / \mathrm{Al}_{2} \mathrm{O}_{3}$ and $\mathrm{Mo} / \mathrm{TiO}_{2}$ but for both edge contributions at once [35]. Additionally, the molar extinction coefficient of M-edge sites with low sulfur coverage appearing at $2098 \mathrm{~cm}^{-1}$ was also calculated on $\mathrm{Mo} / \mathrm{TiO}_{2}$ catalyst to be $21 \mathrm{~mol}^{-1} \cdot \mathrm{cm}$ versus $16 \mathrm{~mol}^{-1} \cdot \mathrm{cm}$ for the component at $2110 \mathrm{~cm}^{-1}$. Hence, there is not a drastic difference between both values. Therefore, only one epsilon is used for the quantification of the M-edge sites (resulting calculated error was 4\%).
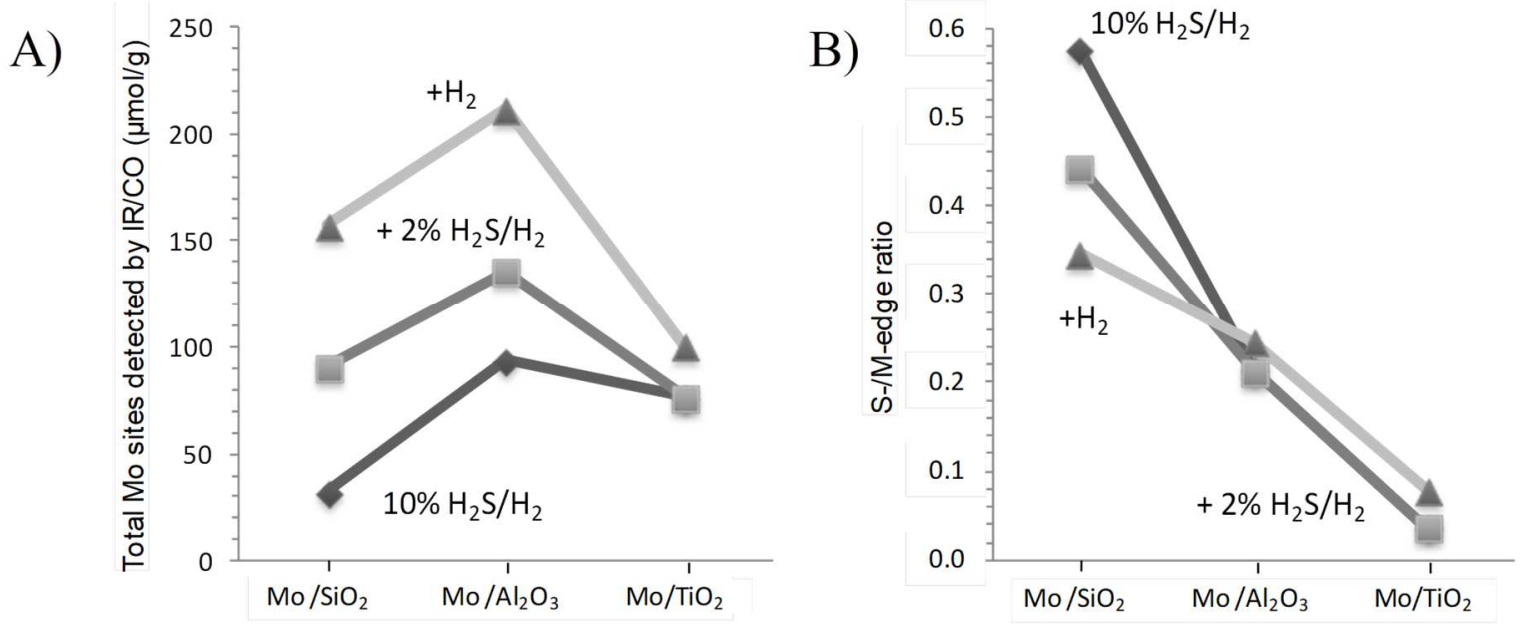

Figure 12. Effect of the sulfo-reductive treatments on A) Total Mo sites and B) S-/M-edge ratio detected by IR/CO for $\mathrm{Mo}_{\mathrm{Al}} \mathrm{l}_{2} \mathrm{O}_{3}, \mathrm{Mo} / \mathrm{SiO}_{2}$ and $\mathrm{Mo} / \mathrm{TiO} \mathrm{O}_{2}$

After spectral de composition and application of the molar extinction coefficients, the total amount of Mo sites and the S-/M-edge ratio were calculated for the three catalysts after the various treatments (Figure 12A and B). As mentioned before, the greater the $\mathrm{H}_{2}$ partial pressure of the post-treatments, the greater the amount of Mo CUS sites detected. As shown on Figure 
$12 \mathrm{~A}$, the extent of the effect depends on the support nature. Thus, the amount of Mo sites increase between the post-treatment under $\mathrm{H}_{2}$ and the sulfidation by $10 \% \mathrm{H}_{2} \mathrm{~S} / \mathrm{H}_{2}$ reaches a factor 5 for $\mathrm{Mo} / \mathrm{SiO}_{2}$, a factor 2 for $\mathrm{Mo} / \mathrm{Al}_{2} \mathrm{O}_{3}$ and only a factor 1.3 for $\mathrm{Mo} / \mathrm{TiO}_{2}$.

These supplementary sites are created both on M-edge and S-edge sites, but not with the same extent. For $\mathrm{Mo} / \mathrm{Al}_{2} \mathrm{O}_{3}$ and for $\mathrm{Mo} / \mathrm{TiO}_{2}, \mathrm{H}_{2}$ treatment induces a very limited change in S/M-edge ratio while it decreases significantly the $\mathrm{S}$-edge proportion for $\mathrm{Mo} / \mathrm{SiO}_{2}$.

The increase of Mo sites amount detected after $2 \% \mathrm{H}_{2} \mathrm{~S} / \mathrm{H}_{2}$ treatment is smaller (even does not change as for $\mathrm{Mo} / \mathrm{TiO}_{2}$ ). For $\mathrm{Mo} / \mathrm{Al}_{2} \mathrm{O}_{3}$ (as well as for $\mathrm{Mo} / \mathrm{TiO}_{2}$ ), no change in S-/M-edge ratio is noted. Unlikely, $\mathrm{Mo} / \mathrm{SiO}_{2}$ presents a $\mathrm{S}$-/M-edge ratio intermediate between that measured after $10 \% \mathrm{H}_{2} \mathrm{~S} / \mathrm{H}_{2}$ and that after $\mathrm{H}_{2}$ treatment.

\subsubsection{Transmission Electron Microscopy (TEM)}

Transmission Electron Microscopy (TEM) was used to determine the average slab length and stacking number of $\mathrm{MoS}_{2}$ slabs after ex situ sulfidation. Representative pictures for Mo catalysts supported on $\mathrm{Al}_{2} \mathrm{O}_{3}, \mathrm{SiO}_{2}$ and $\mathrm{TiO}_{2}$ are shown on Figure 13. The average length and stacking of $\mathrm{MoS}_{2}$ slabs are shown in Table 2. The slab length increases in the order $\mathrm{Mo} / \mathrm{Al}_{2} \mathrm{O}_{3}<$ $\mathrm{Mo} / \mathrm{SiO}_{2}<\mathrm{Mo} / \mathrm{TiO}_{2}$ while the stacking number increases in the order $\mathrm{Mo} / \mathrm{Al}_{2} \mathrm{O}_{3}<\mathrm{Mo} / \mathrm{TiO}_{2}<$ $\mathrm{Mo} / \mathrm{SiO}_{2}$. Note that the slab length for $\mathrm{TiO}_{2}$ has a much larger precision interval due to the small number of observable slabs and that the distribution in size is also wider (not shown). Even though, ranking of the slab length is in accordance with the ranking of the size of the MoOx clusters as determined by UV-vis characterization.
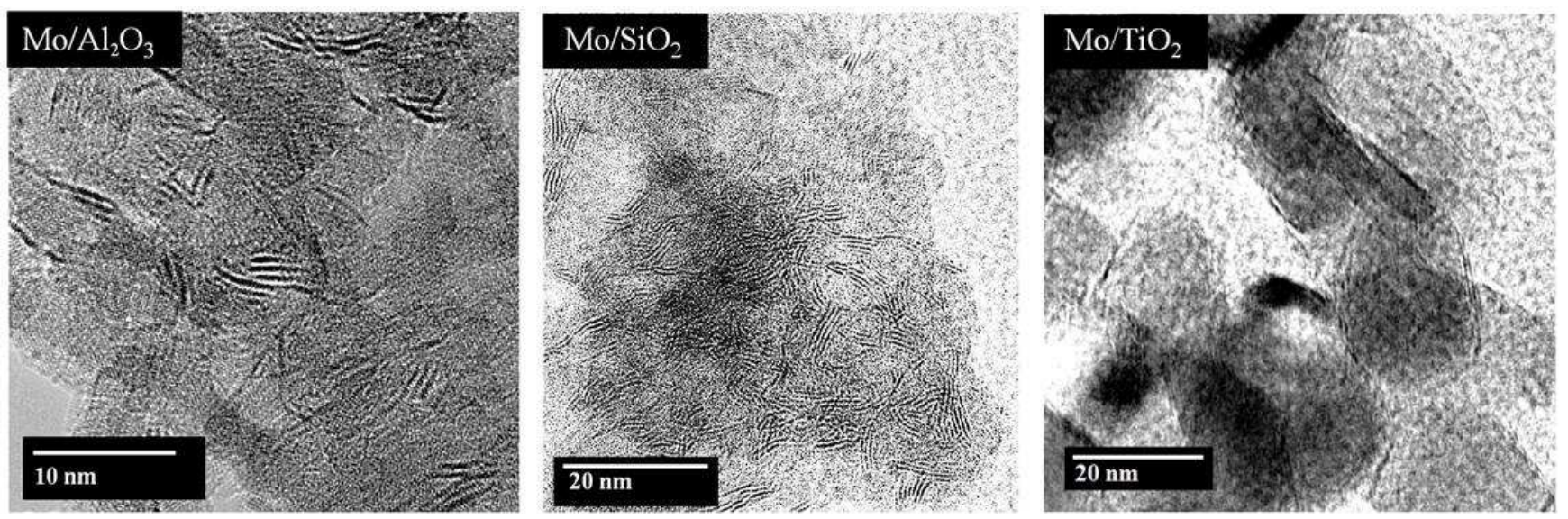

Figure 13. TEM images of $\mathrm{MoS}_{2}$ slabs after standard sulfidation. 
Table 2: Average values of stacking and length of $\mathrm{MoS}_{2}$ slabs after ex-situ sulfidation

\begin{tabular}{|c|c|c|}
\hline Catalyst & Average length $(\mathrm{nm})$ & Average stacking \\
\hline $\mathrm{Mo} / \mathrm{Al}_{2} \mathrm{O}_{3}$ & $1.95 \pm 0.06$ & $1.28 \pm 0.06$ \\
\hline $\mathrm{Mo} / \mathrm{SiO}_{2}$ & $4.67 \pm 0.07$ & $3.50 \pm 0.08$ \\
\hline $\mathrm{Mo} / \mathrm{TiO}_{2}$ & $6.78 \pm 0.39$ & $2.10 \pm 0.19$ \\
\hline
\end{tabular}

\section{Discussion}

The goal of this work is to study the parameters linked to the support that influence the structure of $\mathrm{MoS}_{2}$ slabs in order to get a rational view of the so called slab-support interaction. In this aim, the catalysts were studied at different stages of the preparation starting from the support itself, followed by the oxidic form of the catalysts and finally up to the sulfide catalysts. Table 3 summarizes the main results.

Table 3. Summary of the characteristics of the oxidic or sulfided catalysts

\begin{tabular}{|c|c|c|c|c|}
\hline \multirow{2}{*}{ Catalysts } & Oxide catalyst & \multicolumn{3}{|c|}{ Sulfided catalyst } \\
\cline { 2 - 5 } & $\begin{array}{c}\text { Mo species/ } \\
\text { cluster size }\end{array}$ & $\begin{array}{c}\text { Slab } \\
\text { length }\end{array}$ & Slab stacking & $\begin{array}{c}\text { Sensitivity to sulfo- } \\
\text { reductive treatments }\end{array}$ \\
\hline $\mathrm{Mo} / \mathrm{SiO}_{2}$ & $\begin{array}{c}\mathrm{MoO}_{3} \text { and } \\
\text { polymolybdate }\end{array}$ & Medium & High & High \\
\hline $\mathrm{Mo}^{2} \mathrm{Al}_{2} \mathrm{O}_{3}$ & $\begin{array}{c}\text { Polymolybdate } \\
\text { (small clusters) }\end{array}$ & Low & Low & Medium \\
\hline $\mathrm{Mo} / \mathrm{TiO}_{2}$ & $\begin{array}{c}\text { Polymolybdate } \\
\text { (large cluster) }\end{array}$ & High & Medium & Very low \\
\hline
\end{tabular}




\subsection{Mo-Support interaction in oxidic catalysts}

The support surface was characterized by IR/CO to determine the acidic sites available on the surface of the three supports and then to highlight the possible differences in the interaction between the Mo precursor and the support surface during the impregnation step. The case of the alumina support has been extensively studied due to its widespread industrial use. It is well known that $\mathrm{Al}_{2} \mathrm{O}_{3}$ surface is constituted by hydroxyl groups with different acido-basic properties, and by Lewis acid sites, $\mathrm{Al}^{3+}$ cations. Reactive adsorption has been reported between the basic $\mathrm{OH}$ groups and the heptamolybdate anions at low loading of Mo $\left(<0.6 \mathrm{Mo}\right.$ at. $\left.\mathrm{nm}^{-2}\right)$ leading to irreversible adsorption of tetrahedral monomolybdate anions. Reversible adsorption on $\mathrm{Al}^{3+}$ CUS sites and/or protonated hydroxyls is then considered to occur at higher loading . Moreover, for Mo loading (between 0.6 and 3.5 Mo at. $\mathrm{nm}^{-2}$ ), the formation of the so-called AlMo6 polyanions during the impregnation stage is expected [26]. Blanchard et al. reported that after calcination and contact with air, these anions remain on the oxidic form of the catalyst. The characteristic Raman spectrum of such species shows mainly contributions at 952, 560 and $350 \mathrm{~cm}^{-1}$. These features are close to the ones observed in this work. However, a contribution at $860 \mathrm{~cm}^{-1}$ also clearly appears in our case. For this reason, from the Raman results, we only consider that polymolybdates are formed on the oxidic catalyst on alumina support with terminal vibrations $\left(v_{\mathrm{Mo}}=\mathrm{O}\right)$ giving rise to the peak at $955 \mathrm{~cm}^{-1}$ and bridge vibrations ( $v_{\mathrm{Mo}-\mathrm{O}-\mathrm{Mo}}$ ) to the one at $860 \mathrm{~cm}^{-1}$. From the characterization of the oxidic catalyst by UV-visible, it can be infer that these polymolybdates are small anions such as $\mathrm{Mo}_{2} \mathrm{O}_{7}{ }^{2-}$. According to the IR results, these polymolybdate species are in interaction with both $\mathrm{Al}^{3+} \mathrm{CUS}$ sites and $\mathrm{OH}$ groups.

On $\mathrm{TiO}_{2}$ surface, the decrease of the $\mathrm{CO} / \mathrm{Ti}^{4+}$ stretching band for the calcined catalyst in comparison with the support alone indicates the anchorage of oxomolybdate species on $\mathrm{Ti}^{4+}$ CUS sites in accordance with previous results reported by van Veen et al. on the interaction of heptamolybdate solution with $\mathrm{TiO}_{2}$ [37, 38]. Thus, the so-called strong metal-support interaction reported in the case of $\mathrm{Mo} / \mathrm{TiO}_{2}$ can be explained as resulting from the high density of Lewis acid sites ( $\mathrm{Ti}^{4+}$ CUS sites) of this support compared to the other ones. Moreover, the Raman results indicate the strong metal-support interaction on $\mathrm{TiO}_{2}$ through the detection of the vibration band shift of $10 \mathrm{~cm}^{-1}$ to higher wavenumber in comparison with the other two catalysts. Additionally, the formation of polymolybdate species are confirmed with a lower $\mathrm{Mo}=\mathrm{O} / \mathrm{Mo}-\mathrm{O}-\mathrm{Mo}$ peak ratio than in the case of $\mathrm{Al}_{2} \mathrm{O}_{3}$ indicating that bigger cluster anions are 
formed on $\mathrm{TiO}_{2}$. This result is confirmed by the UV-visible study. Polymolybdates with high number of Mo nearest neighbors are formed on $\mathrm{TiO}_{2}$.

Finally, $\mathrm{SiO}_{2}$ surface only presents weakly acid hydroxyl groups. Thus, specific interaction with the Mo anions is not favored. Accordingly, the dispersion of molybdenum on $\mathrm{SiO}_{2}$ is low and formation of $\mathrm{MoO}_{3}$ is revealed by Raman spectroscopy. The poor molybdenum dispersion is also revealed by the decrease in surface area after the calcinations step. Then, the remaining polymolybdates species are close to the initial $\mathrm{Mo}_{7} \mathrm{O}_{24}{ }^{6-}$ anions according to low $\mathrm{Mo}=\mathrm{O} / \mathrm{Mo}-\mathrm{O}-$ Mo ratio detected in Raman spectrum and to the UV-visible results.

In conclusion for the oxidic forms, the interaction of the Mo species is clearly different on the three studied supports. A strong and specific interaction between polymolybdate species and $\mathrm{Ti}^{4+}$ CUS sites of $\mathrm{TiO}_{2}$ is explained by the presence of high concentration of Lewis acid sites. Interaction of intermediate strength with $\mathrm{OH}$ and Lewis acid sites occur on alumina. And on $\mathrm{SiO}_{2}$, weak interaction with acid hydroxyl groups is observed. Consequently, already in the oxidic catalysts, different Mo species are formed.

\subsection{Support effect on the morphology of $\mathrm{MoS}_{2}$ slabs and Mo edge dispersion}

\subsubsection{Influence of the support on the post-treatment effect on the Mo edge sites}

$\mathrm{CO} / \mathrm{IR}$ was used to characterize the edge sites of $\mathrm{MoS}_{2}$ slabs supported on $\mathrm{Al}_{2} \mathrm{O}_{3}, \mathrm{SiO}_{2}$ and $\mathrm{TiO}_{2}$ after sulfidation under $10 \% \mathrm{H}_{2} \mathrm{~S} / \mathrm{H}_{2}$ and after two different post-treatments (under pure $\mathrm{H}_{2}$ or under $2 \% \mathrm{H}_{2} \mathrm{~S} / \mathrm{H}_{2}$ that is representative of the HDS test conditions). Indeed, DFT calculations predict the influence of temperature and $\mathrm{H}_{2} \mathrm{~S} / \mathrm{H}_{2}$ molar ratio on the sulfur coverage of $\mathrm{MoS}_{2}$ edges $[13,39]$. In the same way, previous IR studies from our group confirm the influence of $\mathrm{H}_{2} \mathrm{~S} / \mathrm{H}_{2}$ molar ratio on the sulfur coverage of the edges of $\mathrm{MoS}_{2}$ slabs supported on $\mathrm{Al}_{2} \mathrm{O}_{3}[10$, $20,40,41]$. In particular, it was shown that the $\mathrm{H}_{2}$ post-treatment leads to an increase of detected Mo CUS sites as well as to the formation of more S-depleted sites as indicated by the shift of the CO/Mo bands to lower wavenumbers [10, 11]. Accordingly, in this study, an increase of Mo sites detected by $\mathrm{CO}$ has been observed after the $\mathrm{H}_{2}$ post-treatment for the three Mo catalysts whatever the nature of the support. This increase is well explained by the formation of Mo CUS sites by elimination of sulfur on the edge during the $\mathrm{H}_{2}$ post-treatment. However, it is noticeable that the magnitude of the increase varies significantly with the support nature: the strongest effect was recorded for $\mathrm{Mo} / \mathrm{SiO}_{2}$, followed by $\mathrm{Mo} / \mathrm{Al}_{2} \mathrm{O}_{3}$ and 
finally for $\mathrm{Mo} / \mathrm{TiO}_{2}$. Therefore, the effect of the "reductive" treatment on the Mo CUS formation can be related to the strength of the metal-support interaction. The sulfur depletion upon $\mathrm{H}_{2}$ treatment is easier in the case of a weak $\mathrm{MoS}_{2}$-support interaction while the strong interaction between $\mathrm{Mo}$ and $\mathrm{TiO}_{2}$ prevents change in the $\mathrm{S}$ coverage of $\mathrm{MoS}_{2}$ slabs. Note that according to Arrouvel et al., the Mo edge sites of $\mathrm{TiO}_{2}$ supported slabs are already highly Sdepleted thus accordingly further reductive treatment will not have a strong effect on the Mo CUS sites formation [8]. It is however observed that for the $\mathrm{Al}_{2} \mathrm{O}_{3}, \mathrm{SiO}_{2}$ and $\mathrm{TiO}_{2}$ supported catalysts, the main $v(\mathrm{CO} / \mathrm{M}$-edge $)$ band is downward shifted after $\mathrm{H}_{2}$ treatment of respectively 4, 6 and $7 \mathrm{~cm}^{-1}$. In the specific case of $\mathrm{TiO}_{2}$, one can also propose a reduction of surface $\mathrm{Ti}^{4+}$ cations to $\mathrm{Ti}^{3+}$, that would modify the $\mathrm{MoS}_{2}$ electronic state and thus shift the $v(\mathrm{CO} / \mathrm{M}$-edge $)$ band to lower wavenumber.

The appearance of a supplementary CO/Mo band at lower wavenumbers can also account for the decrease of sulfur coverage of the Mo sites [22]. Indeed, after $\mathrm{H}_{2}$ treatment, a new component downward shifted of about $8-13 \mathrm{~cm}^{-1}$ from the main band is detected. Such $\mathrm{S}$ depleted sites would be formed as well on $\mathrm{Mo} / \mathrm{TiO}_{2}$ even if limited increase of total Mo CUS sites is obtained.

Although the effects are less marked for the $2 \% \mathrm{H}_{2} \mathrm{~S} / \mathrm{H}_{2}$ post-treatment, such conditions are more representative of thiophene HDS conditions. In this case, for $\mathrm{Mo} / \mathrm{Al}_{2} \mathrm{O}_{3}$ and $\mathrm{Mo} / \mathrm{SiO}_{2}$ catalysts, as expected a limited increase of detected Mo site was observed compared to standard sulfidation. No influence of such decrease of $\mathrm{H}_{2} \mathrm{~S}$ partial pressure was found for $\mathrm{Mo} / \mathrm{TiO}_{2}$. Moreover, in all cases any band shift was detected after $2 \% \mathrm{H}_{2} \mathrm{~S} / \mathrm{H}_{2}$ post-treatment meaning that the $\mathrm{S}$ depletion in the environment of the adsorbing sites is indeed limited, and that conditions are not enough reductive to reduce titania support.

\subsubsection{Effect of the support on the morphology (shape, length and stacking) of}

\section{$\mathrm{MoS}_{2}$ slabs}

In the following only the IR/CO results obtained after the $2 \% \mathrm{H}_{2} \mathrm{~S} / \mathrm{H}_{2}$ post-treatment will be considered. From the comparison of the IR/CO spectra obtained for the three catalysts ((Error! Reference source not found. $), v(\mathrm{CO} / \mathrm{M}$-edge $)$ it appears that the ratio between the $v(\mathrm{CO} / \mathrm{M}$ edge) and $v(\mathrm{CO} / \mathrm{S}$-edge $)$ bands strongly depends on the catalysts. This highlights that, for sulfidation performed in similar conditions, the $\mathrm{MoS}_{2}$ slab morphology strongly depends on the support. Accordingly, the S-/M-edge ratio increases in the order $\mathrm{Mo} / \mathrm{TiO}_{2}<\mathrm{Mo} / \mathrm{Al}_{2} \mathrm{O}_{3}<$ $\mathrm{Mo} / \mathrm{SiO}_{2}$ (Figure 12). This order is in relation with the strength of metal-support interaction. 
The predominance of M-edge sites on $\mathrm{Mo} / \mathrm{TiO}_{2}$ is in accordance with the DFT studies carried out by Costa et al [7]. TEM analysis also reveals the difference in stacking and length of $\mathrm{MoS}_{2}$ slabs according to the support nature. The slab stacking increases in the order $\mathrm{Mo} / \mathrm{Al}_{2} \mathrm{O}_{3}<$ $\mathrm{Mo} / \mathrm{TiO}_{2}<\mathrm{Mo} / \mathrm{SiO}_{2}$, with 1,2 and 4 average stacking values, respectively. The high stacking of $\mathrm{Mo} / \mathrm{SiO}_{2}$ can be linked with the weak metal-support interaction as previously proposed. The slab length increases in the order $\mathrm{Mo} / \mathrm{Al}_{2} \mathrm{O}_{3}<\mathrm{Mo} / \mathrm{SiO}_{2}<\mathrm{Mo} / \mathrm{TiO}_{2}$, with 2.0 , 4.7 and $6.7 \mathrm{~nm}$ average values, respectively. Interestingly, this evolution order for $\mathrm{MoS}_{2}$ slab length is in line with the size domain of the oxidic Mo clusters as characterized by UV-visible spectroscopy.

The average of slab length (LTEM) from TEM images and S-edge/M-edge ratio from IR/CO were then taken into account to describe the "average" $\mathrm{MoS}_{2}$ slab morphology in the three catalysts. Mo-Mo distance (3.16 ̊) was taken to calculate the number of molybdenum atoms $\left(\mathrm{n}_{\mathrm{L}}\right)$ forming the longer line that is detected by TEM microscopy ( $\left.\mathrm{L}_{\mathrm{TEM}}\right)$, and S-edge/M-edge ratio from IR/CO was considered to calculate the number of molybdenum present in $\mathrm{M}-\left(\mathrm{n}_{\mathrm{M}}\right)$ and S-edge $\left(\mathrm{n}_{\mathrm{S}}\right)$ in $\mathrm{MoS}_{2}$ slab edges. The slab is considered flatly in interaction with the support. The corner sites are considered half as M-edge sites and half as S-edge sites. The equations used are:

$$
\begin{aligned}
& \mathrm{n}_{\mathrm{L}}=\mathrm{L}_{\mathrm{TEM}} / 0.316 \text { with } \mathrm{L}_{\mathrm{TEM}} \text { in } \mathrm{nm} \text {. } \\
& \mathrm{n}_{\mathrm{L}}-1=\mathrm{n}_{\mathrm{S}}+\mathrm{n}_{\mathrm{M}}
\end{aligned}
$$

\section{S- /M-edge ratio from IR/CO $=\mathrm{n}_{S} / \mathrm{n}_{\mathrm{M}}$}

The result of the predicted morphologies considering this regular model is shown in Figure highlighting the strong differences in the slab characteristics versus the support: an almost perfect hexagon is deduced for $\mathrm{Mo} / \mathrm{SiO}_{2}$, truncated triangle for $\mathrm{Mo} / \mathrm{Al}_{2} \mathrm{O}_{3}$ and an almost perfect triangle for $\mathrm{Mo} / \mathrm{TiO}_{2}$. Then, Mo edge dispersion can be calculated from this global slab morphology for the three supports. Both the slab length obtained by TEM and the morphology influence Mo edge dispersion [42]: the longer the slab the lower the Mo edge dispersion. For a similar slab length, Mo edge dispersion is higher for triangular than for hexagonal shape. 


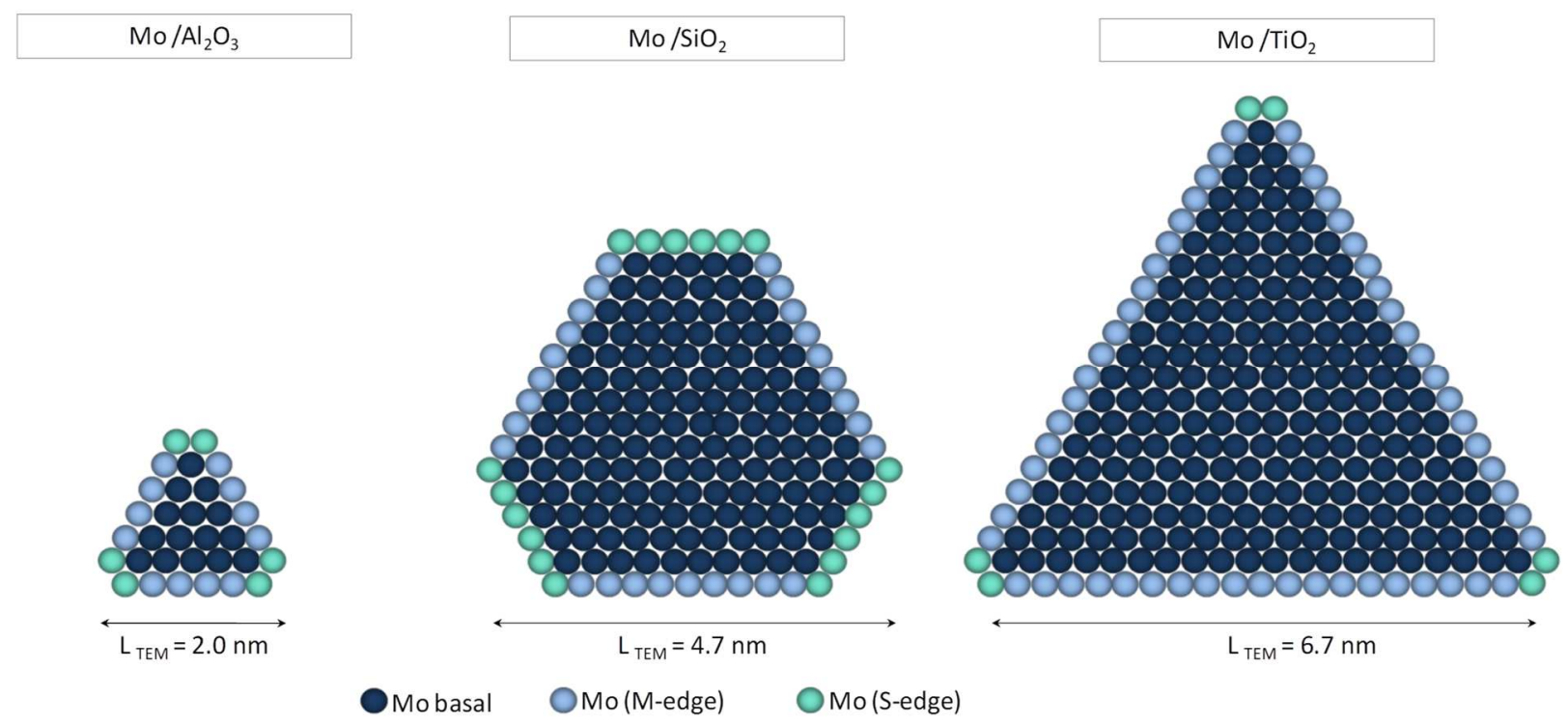

Figure 14. Schemes of the $\mathrm{MoS}_{2}$ slabs supported on alumina, silica and titania deduced from IR/CO spectroscopy and TEM data

Then, the concentration of total Mo edge sites can be calculated taking into account the total Mo concentration obtained from ICP analysis, the slab length from TEM and the $\mathrm{MoS}_{2}$ shape obtained by IR/CO (Table 4). High Mo edge dispersion was calculated for $\mathrm{Mo} / \mathrm{Al}_{2} \mathrm{O}_{3}$ due to its small particle size and slab shape close to a triangle. Instead, Mo sites amount is low for $\mathrm{Mo} / \mathrm{SiO}_{2}$ due to the high nanoparticles size and the hexagon morphology. Although $\mathrm{Mo} / \mathrm{SiO}_{2}$ and $\mathrm{Mo} / \mathrm{TiO}_{2}$ present different particle size, calculation gives an equivalent and small amount of Mo edge dispersion for both catalysts. The similar Mo dispersion is explained by the compensation of the triangle morphology by the high average slab length for $\mathrm{Mo} / \mathrm{TiO}_{2}$ compared with $\mathrm{Mo} / \mathrm{SiO}_{2}$.

The Mo edge site concentration obtained by direct quantitative IR/CO method is compared with the one calculated from the slab scheme given the $\mathrm{MoS}_{2}$ slab length and shape obtained by TEM and IR/CO respectively (Table 4). The ratio between the direct quantification and the calculated one is around $40 \%$ for Mo supported on $\mathrm{Al}_{2} \mathrm{O}_{3}$ and $\mathrm{SiO}_{2}$ catalysts, such values being in the usual range [10]. Surprisingly, value of sites probed by $\mathrm{CO}$ is higher than the one calculated from the slab scheme for $\mathrm{Mo} / \mathrm{TiO}_{2}$ catalyst. This high proportion can be first explained taking into account the high depletion in $\mathrm{S}$ of the exposed M-edge for this sample, leading to high Mo CUS concentration. Note that the accuracy of the IR/CO detection has been assessed for this catalyst, checking the validity of the epsilon value. The discrepancy may then come from the value of the slab length determined on a lesser slab number than for the two 
other catalysts. However, even taking into account the lower value of the confidence interval for the slab length, the proportion of sites detected by IR/CO would be greater than one. Then, there are probably smaller slabs that cannot be distinguished from the support by TEM. Note that the sulfidation rate was not taken into account for this calculation but independent work on similar results has shown that it was close to 0.8 for the three catalysts [47].

Table 4. Comparison between Mo edge calculated by TEM ${ }^{1}$ results and Mo detected by IR/CO

\begin{tabular}{|c|c|c|c|c|c|}
\hline Catalyst & $\mathrm{A}$ & $\mathrm{B}$ & $\mathrm{AxB}$ & $\mathrm{D}$ & $\mathrm{D} /(\mathrm{AxBxC})$ \\
\hline $\begin{array}{c}\text { Total Mo } \\
\text { by ICP } \\
(\mu \mathrm{mol} / \mathrm{g})\end{array}$ & $\begin{array}{c}\text { Edge } \\
\text { dispersion } \\
\text { from slab } \\
\text { scheme }\end{array}$ & $\begin{array}{c}\text { Mo edge } \\
\text { concentration } \\
(\mu \mathrm{mol} / \mathrm{g})\end{array}$ & $\begin{array}{c}\text { Mo edge by } \\
\text { IR/CO }(\mu \mathrm{mol} / \mathrm{g}) \\
\text { after } \mathrm{H}_{2} \text { post- } \\
\text { treatment }\end{array}$ & $\begin{array}{c}\text { Ratio of Mo } \\
\text { edge } \\
\text { concentration } \\
\text { detected by } \\
\text { IR/CO }\end{array}$ \\
\hline $\mathrm{Mo} / \mathrm{Al}_{2} \mathrm{O}_{3}$ & 1115 & 0.54 & 602 & 212 & 0.35 \\
\hline $\mathrm{Mo} / \mathrm{SiO}_{2}$ & 1699 & 0.24 & 408 & 157 & 0.39 \\
\hline $\mathrm{Mo} / \mathrm{TiO}_{2}$ & 250 & 0.23 & 60 & 100 & 1.74 \\
\hline
\end{tabular}

\subsection{Influence of the $\mathrm{MoS}_{2}$ morphology on the catalytic activity}

Recently, several studies showed the relation between total Mo sites, and $\mathrm{MoS}_{2}$ morphology with the catalytic activity [10, 43, 44]. These two parameters were reported to be the main ones influencing catalytic activity. Accordingly, for the present study, the relation between the amount of Mo sites detected by IR/CO per support surface unit and catalytic activity per support surface unit is shown in Figure A. This comparison is chosen to compare the catalysts with the same metal density $\left(3\right.$ at. $\left.\mathrm{nm}^{-2}\right)$. Note that due to the difference in support surface area, the order of Mo edge concentration is modified as compared to the one given per gram of catalyst.

Thus, a tendency between total Mo sites and HDS rate was found, since the higher the Mo site concentration the higher the catalytic activity. The highest activity was found for $\mathrm{Mo} / \mathrm{TiO}_{2}$ catalyst, followed by $\mathrm{Mo} / \mathrm{Al}_{2} \mathrm{O}_{3}$ catalyst, and finally $\mathrm{Mo} / \mathrm{SiO}_{2}$ catalyst. Then, the high activity of $\mathrm{Mo} / \mathrm{TiO}_{2}$ that can be linked with the high amount of Mo sites detected, confirms the reliability of the IR/CO measurements on this catalyst. However, no linear relationship is obtained underlying that the probed sites do no present the same intrinsic activity. This intrinsic 
activity (TOF value) can be roughly estimated by dividing the global activity by the total site concentration for each catalyst.

A)

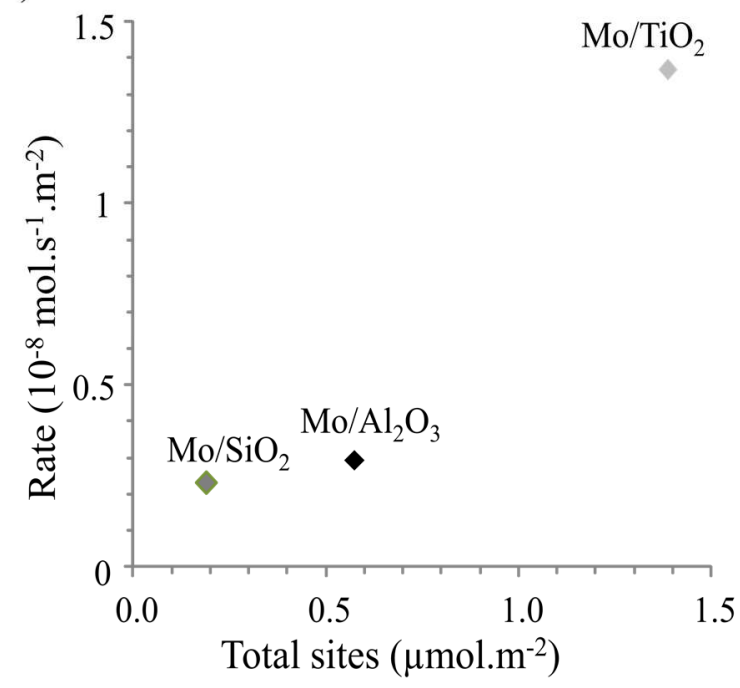

B)

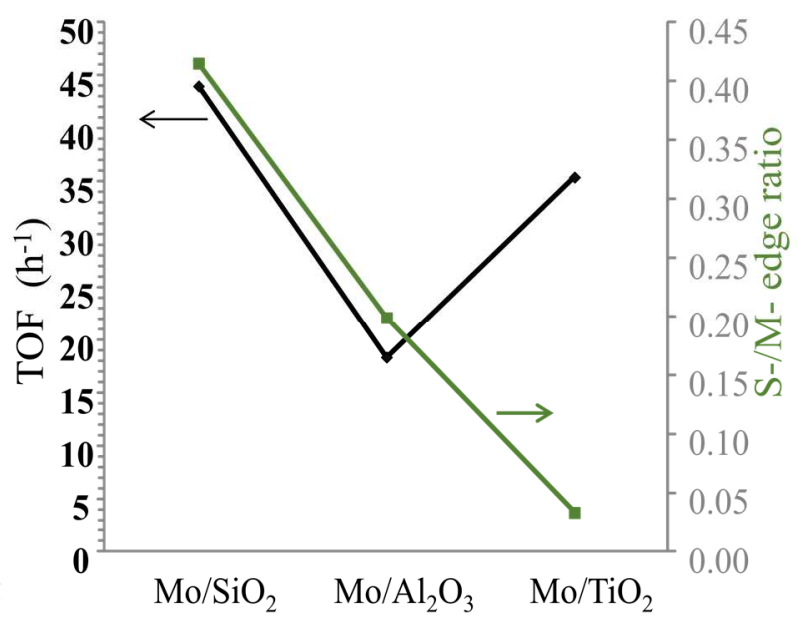

Figure 15. A) Relationship between $\mathrm{HDS}$ rate and total amount of sites for $\mathrm{Mo} / \mathrm{Al}_{2} \mathrm{O}_{3}, \mathrm{Mo} / \mathrm{SiO}_{2}$ and $\mathrm{Mo} / \mathrm{TiO}_{2}$. The total amount of sites is measured by IR/CO after $2 \% \mathrm{H}_{2} \mathrm{~S} / \mathrm{H}_{2}$ post-treatment. B) Total TOF value and S-M-edge ratio taking into account the sites detected after $2 \% \mathrm{H}_{2} \mathrm{~S} / \mathrm{H}_{2}$ post-treatment for Mo supported on $\mathrm{Al}_{2} \mathrm{O}_{3}, \mathrm{SiO}_{2}$ and $\mathrm{TiO}_{2}$.

For the three catalysts, the variation of these TOF values and of the S-/M-edge ratio is given in Error! Reference source not found. For $\mathrm{Mo} / \mathrm{Al}_{2} \mathrm{O}_{3}$ and $\mathrm{Mo} / \mathrm{SiO}_{2}$ an increase of TOF value was detected in parallel with the increase of S-/M-edge ratio as was expected from previous study [11]. The case of $\mathrm{Mo} / \mathrm{TiO}_{2}$ is particular with a high value of TOF while the S/M- ratio is low. Note that this TOF value is obtained even though concentration of sites detected by IR/CO was surprisingly high. Such high TOF value of $\mathrm{Mo} / \mathrm{TiO}_{2}$ sites has been previously reported by Ninh et al, both for thiophene and DBT HDS reactions [32] after site quantification by XPS and TEM considering hexagonal shaped slabs. It appears from both studies that the active sites in the case of $\mathrm{Mo} / \mathrm{TiO}_{2}$ are of a particular nature. This specific behavior should be linked to the strong $\mathrm{MoS}_{2}-\mathrm{TiO}_{2}$ interaction revealed at the early stage of the catalyst preparation. 


\section{Conclusion}

A clear and important support effect was evidenced in $\mathrm{MoS}_{2}$ nanoparticles formation. The metal-support interaction starting at the impregnation stage strongly impacts the formation of $\mathrm{MoS}_{2}$ slabs (stacking, length, morphology) and influences their reactivity.

Indeed, when Mo precursor interacts with weakly acidic hydroxyl group as on silica, oxomolybdenum species are poorly dispersed and favored $\mathrm{MoO}_{3}$ species formation. If Mo precursor is in interaction with basic hydroxyl groups and Lewis acid sites as on alumina, the metal-support interactions are stronger and dispersion of polymolybdate species is detected by Raman and UV-Vis spectroscopies. As for titania, strong metal-support interactions occur with molybdenum precursor interacting mainly with Lewis acid sites present in high density. This strong interaction is testified by the shift to higher wavenumbers of polymolybdate characteristic vibrations detected by Raman. In such a case, large $\mathrm{MoO}_{\mathrm{x}}$ clusters are formed but avoiding $\mathrm{MoO}_{3}$ formation. This first stage has a key effect on the genesis of the sulfide phase, and can strongly change the morphology, activity and selectivity of the resulting $\mathrm{MoS}_{2}$ slabs. Near to perfect hexagonal sulfide slabs with high stacking and high slab length were detected for $\mathrm{Mo} / \mathrm{SiO}_{2}$ catalyst, which lead to low Mo edge dispersion. Truncated triangle sulfide slabs were observed for $\mathrm{Mo} / \mathrm{Al}_{2} \mathrm{O}_{3}$ with mono-stacking and small slab lengths, which lead to high Mo edge dispersion. For alumina and silica supported catalysts, the thiophene HDS activity can be related to the concentration of Mo edge sites and to the S-/M-edge ratio in accordance with the S-edge sites having a greater TOF value than M-edge sites as previously reported.

Thus, for Mo catalysts supported on silica and alumina, the most active catalyst should present both a good dispersion and a morphology that favors the S-edges. However, a different behavior was found for $\mathrm{Mo} / \mathrm{TiO}_{2}$ catalyst. The highest TOF was found for this catalyst even though it is mainly composed of Mo sites on M-edge. Thus, the strong interaction between $\mathrm{MoS}_{2}$ slab and $\mathrm{TiO}_{2}$ gives rise to specific M-edge sites with high specific activity and high selectivity towards HYD pathway.

Acknowledgement 
E. Dominguez Garcia thanks the financial support of the French Ministry of Research through her $\mathrm{PhD}$ grant. J. Chen thanks the financial support of The Natural Science Foundation of China (No. 21606047). G. Clet is thanked for the Raman characterization.

\section{References}

[1] H. Topsoe, B.S. Clausen, F.E. Massoth, Hydrotreating Catalysis, Sciences and Technology Springer-Verlag, Berlin/New York, 1996.

[2] M. Breysse, C. Geantet, P. Afanasiev, J. Blanchard, M. Vrinat, Catal. Today 130 (2008) 3-13.

[3] M. Breysse, M. Cattenot, V. Kougionas, J.C. Lavalley, F. Mauge, J.L. Portefaix, J.L. Zotin, J. Catal. 168 (1997) 143-153.

[4] A.S. Rocha, A.C.J. Faro, L. Oliviero, M.A. Lélias, A. Travert, J. van Gestel, F. Maugé, Catal. Letters 111 (2006) 27-34.

[5] M. Breysse, P. Afanasiev, C. Geantet, M. Vrinat, Catal. Today 86 (2003) 5-16.

[6] J. Ramirez, G. Macias, L. Cedeno, A. Gutierrez-Alejandre, R. Cuevas, P. Castillo, Catal. Today 98 (2004) 19-30.

[7] D. Costa, C. Arrouvel, M. Breysse, H. Toulhoat, P. Raybaud, J. Catal. 246 (2007) 325343.

[8] C. Arrouvel, M. Breysse, H. Toulhoat, P. Raybaud, J. Catal. 232 (2005) 161-178.

[9] Y.V. Joshi, P. Ghosh, M. Daage, W.N. Delgass, J. Catal. 257 (2008) 71-80.

[10] C. Dujardin, M.A. Lelias, J. van Gestel, A. Travert, J.C. Duchet, F. Mauge, Appl. Catal. A 322 (2007) 46-57.

[11] J. Chen, F. Mauge, J. El Fallah, L. Oliviero, J. Catal. 320 (2014) 170-179.

[12] S. Kasztelan, H. Toulhoat, J. Grimblot, J.P. Bonnelle, Bull. Soc. Chim. Belg. 93 (1984) 807-811.

[13] H. Schweiger, P. Raybaud, G. Kresse, H. Toulhoat, J. Catal. 207 (2002) 76-87.

[14] P. Raybaud, J. Hafner, G. Kresse, S. Kasztelan, H. Toulhoat, J. Catal. 189 (2000) 129-

146.

[15] P. Raybaud, J. Hafner, G. Kresse, H. Toulhoat, Surf. Sci. 407 (1998) 237-250.

[16] S. Helveg, J.V. Lauritsen, E. Laegsgaard, I. Stensgaard, J.K. Norskov, B.S. Clausen, H. Topsoe, F. Besenbacher, Phys. Rev. Lett. 84 (2000) 951-954.

[17] A.S. Walton, J.V. Lauritsen, H. Topsoe, F. Besenbacher, J. Catal. 308 (2013) 306-318.

[18] J.V. Lauritsen, M.V. Bollinger, E. Laegsgaard, K.W. Jacobsen, J.K. Norskov, B.S. Clausen, H. Topsoe, F. Besenbacher, J. Catal. 221 (2004) 510-522.

[19] J. Kibsgaard, B.S. Clausen, H. Topsoe, E. Laegsgaard, J.V. Lauritsen, F. Besenbacher, J. Catal. 263 (2009) 98-103.

[20] J. Chen, V. Labruyere, F. Mauge, A.-A. Quoineaud, A. Hugon, L. Oliviero, J. Phys. Chem. C 118 (2014) 30039-30044.

[21] F. Mauge, J.C. Lavalley, J. Catal. 137 (1992) 69-76.

[22] A. Travert, C. Dujardin, F. Mauge, E. Veilly, S. Cristol, J.F. Paul, E. Payen, J. Phys. Chem. B 110 (2006) 1261-1270.

[23] A. Travert, C. Dujardin, F. Mauge, S. Cristol, J.F. Paul, E. Payen, D. Bougeard, Catal. Today 70 (2001) 255-269.

[24] M. Fournier, C. Louis, M. Che, P. Chaquin, D. Masure, J. Catal. 119 (1989) 400-414.

[25] N.Y. Topsoe, H. Topsoe, J. Catal. 139 (1993) 631-640. 
[26] P. Blanchard, C. Lamonier, A. Griboval, E. Payen, Appl. Catal. A 322 (2007) 33-45.

[27] S. Dzwigaj, C. Louis, A. Breysse, M. Cattenot, V. Belliere, C. Geantet, M. Vrinat, P. Blanchard, E. Payen, S. Inoue, H. Kudo, Y. Yoshimura, Appl. Catal. B 41 (2003) 181-191.

[28] H.C. Hu, I.E. Wachs, S.R. Bare, J. Phys. Chem. 99 (1995) 10897-10910.

[29] L. Seguin, M. Figlarz, R. Cavagnat, J.C. Lassegues, Spectro. Chem. Acta A 51 (1995) 1323-1344.

[30] R.S. Weber, J. Catal. 151 (1995) 470-474.

[31] L. van Haandel, G.M. Bremmer, E.J.M. Hensen, T. Weber, J. Catal. 351 (2017) 95-106.

[32] T.K.T. Ninh, L. Massin, D. Laurenti, M. Vrinat, Appl. Catal. A 407 (2011) 29-39.

[33] P. Castillo-Villalon, J. Ramirez, R. Cuevas, P. Vazquez, R. Castaneda, Catal. Today 259 (2016) 140-149.

[34] M. Ziolek, J. Kujawa, O. Saur, J.C. Lavalley, Journal of Molecular Catalysis A: Chemical 97 (1995) 49-55.

[35] J. Chen, E.D. Garcia, L. Oliviero, F. Mauge, J. Catal. 332 (2015) 77-82.

[36] P. Castillo-Villalon, J. Ramirez, J. Antonio Vargas-Luciano, J. Catal. 320 (2014) 127-

136.

[37] M.J. Vissenberg, L.J.M. Joosten, M. Heffels, A.J. van Welsenes, V.H.J. de Beer, R.A. van Santen, J.A.R. van Veen, J. Phys. Chem. B 104 (2000) 8456-8461.

[38] J.A.R. Van Veen, E. Gerkema, A.M. Van der Kraan, A. Knoester, Journal of the Chemical Society, Chemical Communications (1987) 1684 - 1686.

[39] P. Raybaud, Appl. Catal. A 322 (2007) 76-91.

[40] J. Chen, E.D. Garcia, E. Oliviero, L. Oliviero, F. Mauge, J. Catal. 339 (2016) 153-162.

[41] L. Oliviero, L. Mariey, M.A. Lelias, S. Aiello, J. van Gestel, F. Mauge, Catal. Letters 135 (2010) 62-67.

[42] S. Kasztelan, H. Toulhoat, J. Grimblot, J.P. Bonnelle, Appl. Catal. 13 (1984) 127-159.

[43] M.A. Lelias, E. Le Guludec, L. Mariey, J. van Gestel, A. Travert, L. Oliviero, F. Mauge, Catal. Today 150 (2010) 179-185.

[44] M.A. Lelias, P.J. Kooyman, L. Mariey, L. Oliviero, A. Travert, J. van Gestel, J.A.R. van Veen, F. Mauge, J. Catal. 267 (2009) 14-23. 
